\title{
Reactions of hydrazonoyl halides with heterocyclic thiones. Convenient methodology for heteroannulation, synthesis of spiroheterocycles and heterocyclic ring transformation
}

\author{
Ahmad Sami Shawali* and Thoraya A. Farghaly \\ Department of Chemistry, Faculty of Science, University of Cairo, Giza, Egypt \\ E-mail:as_shawali@yahoo.com
}

\begin{abstract}
This review summarizes research results concerning the reactions of hydrazonoyl halides with heterocyclic thiones reported by us and other research groups from 1991 to mid 2007. It outlines the utility of such reactions in various aspects of heterocyclic chemistry.
\end{abstract}

Keywords: Nitrilimines, 1,3-dipolar cycloaddition, azolethiones, azinethiones

\section{Contents}

1. Introduction

2. Heteroannulation

2.1 Heteroannulation of monoheterocycles

2.1.1. Imidazolethiones

2.1.2. 1,2,4-Triazolethiones

2.1.3. Pyrimidinethiones

2.1.4. 1,2,4-Triazinethiones

2.1.5. 1,2,4-Triazepinethiones

2.2. Heteroannulation of biheterocycles

2.2.1. Benzimidazolethiones

2.2.2. Purinethiones

2.2.3. Pyrazolo[3,4- $d]$ pyrimidinethiones

2.2.4. Quinazolinethiones

2.2.5. Pyrido[2,3-d]thiouracils

2.2.6. Pteridinethiones

2.2.7. Quinoxalinethiones

2.3. Heteroannulation of triheterocycles

2.3.1. Benzothieno[2,3- $d]$ pyrimidinethiones 
2.3.2. Pyrido[3',2' : 4,5] thieno[2,3- $d]$ pyrimidinethiones

2.3.3. Cyclohepta $[4,5]$ thieno[2,3- $d]$ pyrimidinethiones

2.3.4. Pyrido[2,3- $d: 6,5-d]$ dipyrimidinethiones

2.4. Heteroannulation of tetraheterocycles

2.4.1. Naphtho[2,1-e]pyrido[2,3-c]pyrimidinethiones

3. Synthesis of spiroheterocycles

4. Heterocyclic ring transformations

4.1 Transformation of azetine-2-thiones into 1,3,4-triazoles

4.2 Transformation of 1,3,4-oxadiazole-2(3H)-thiones into 1,3,4-thiadiazoles

4.3 Transformation of 1,4,2-dithiazole-5-thiones into 1,3,4-thiadiazoles

4.4 Transformation of tetrazole-5- $(1 \mathrm{H})$-thiones into 1,3,4-thiadiazoles

4.5 Transformation of tetrazole into 1,2,4,5-tetrazines

5. Functional group transformations

6. Conclusions

7. References

\section{Introduction}

Hydrazonoyl halides are a class of compounds with the general formula 1 where X represents a chlorine or bromine group. These compounds are the acyl halides of the so-called hydrazonoic acids $\mathbf{2}$ as the imidoyl chlorides $\mathbf{3}$ are the chloride derivatives of imidoic acids $\mathbf{4}$ (Chart 1). Since work concerning hydrazonoyl halides $\mathbf{1}$ as synthetic auxilliaries commenced in 1970 in our group, many papers and patents have been published including some reviews by Shawali et al. ${ }^{1-9}$ and by others ${ }^{10}$ concerning their reactions and biological activities. Such reviews have been useful for the chemists and biologists engaged in the development of synthesis of new heterocyclic systems, new drugs or in other important works. The intention of the present review is to cover research results concerning the title reactions reported by us and by other research groups from 1991 to mid 2007 and which have not been reviewed hitheto. The coverage was made through Chemical Abstracts Vols. 114 - 145.

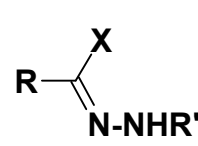

1<smiles>[R]NN=C([R])O</smiles>

2<smiles>[R]N=C([R])Cl</smiles>

3

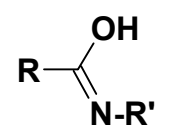

4

\section{Chart 1}


Reactions of hydrazonoyl halides $\mathbf{1}$ are usually carried out in the presence of a base catalyst. The function of the latter is to convert $\mathbf{1}$ into the respective 1,3-dipoles $\mathbf{5}$ which are called nitrilimines or nitrilium imides via 1,3-elimination reaction. The mechanism of this dehydrohalogenation reaction has been studied by Shawali et al. ${ }^{11-13}$ and was shown to be as depicted in Scheme 1.
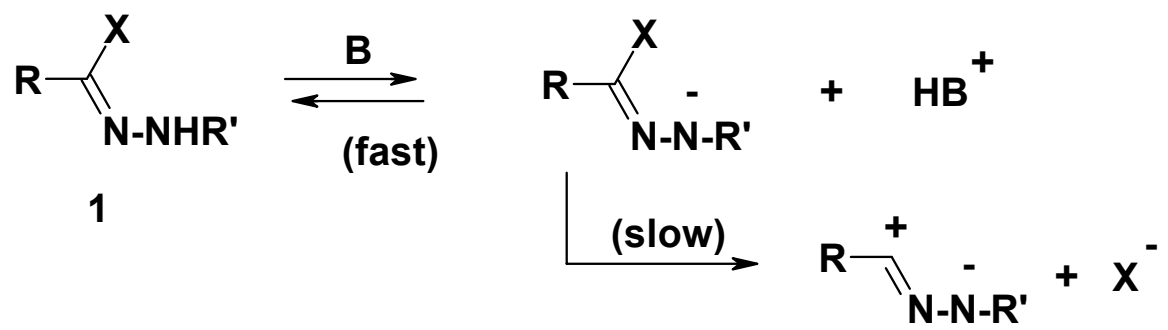

5

\section{Scheme 1}

Reactions of nitrilimines, derived from hydrazonoyl halides, with heterocyclic thiones may proceed via a 1,3-addition or 1,3-dipolar cycloaddition pathway depending on whether the reacting heterocyclic thiones act as protic nucleophiles or dipolarophiles, respectively. This is because thiones of type $\mathbf{6}$ that have $\alpha$-hydrogen can exist in either the tautomeric thione form $\mathbf{6 A}$ or the thiol form 6B. Generally, reactions of nitrilimines with heterocyclic thiones, having the thiol form $\mathbf{6 B}$, start with the formation of the 1,3-adducts to give the respective thiohydrazonate esters 7 as intermediates, whereas reactions of such 1,3-dipoles with true heterocyclic thiones having the thione form $6 \mathrm{~A}$ proceed via 1,3-dipolar cycloaddition to the $\mathrm{C}=\mathrm{S}$ double bond to form the spirocycloadducts namely spirothiadiazoles $\mathbf{8}$ (Scheme 2). Both types of intermediates 7 and 8 usually undergo further in situ reactions according to their structures and the reaction conditions leading thus to either formation of new annelated heterocycles, spiro heterocycles, heterocyclic ring transformation or functional group modification as outlined in the following sections. 


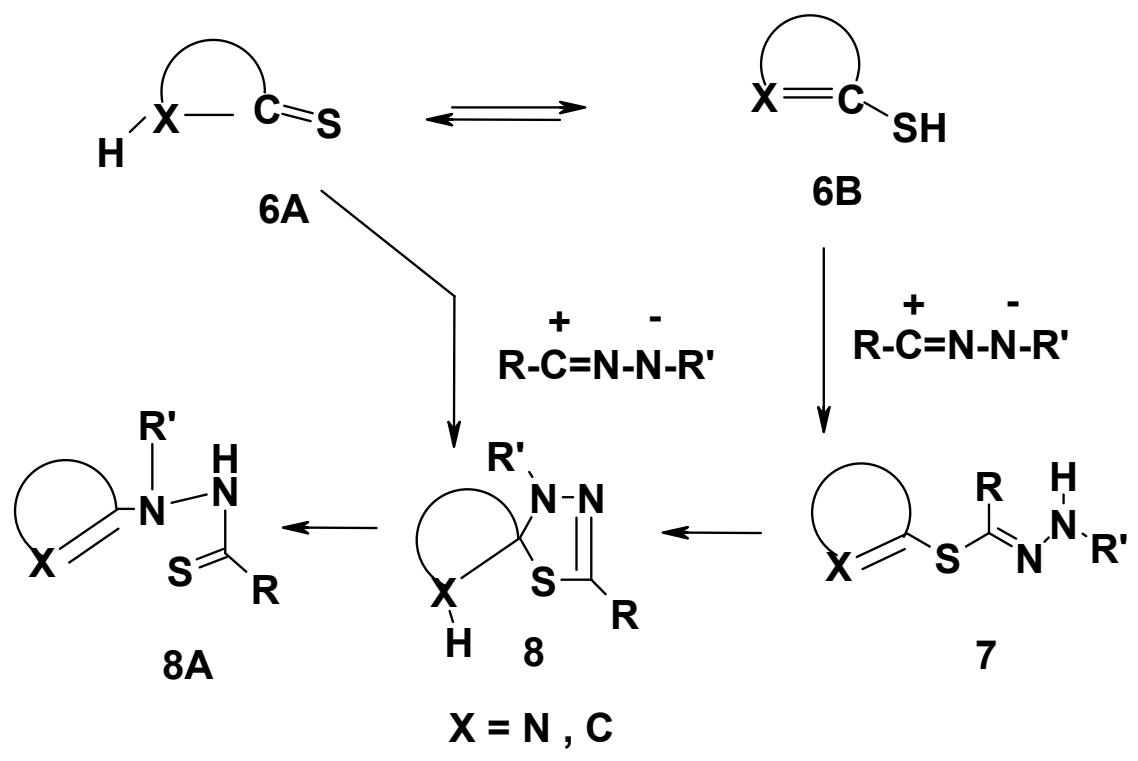

\section{Scheme 2}

In this review, the heterocyclic thiones, whose reactions with hydrazonoyl halides are covered, are presented in order of their increasing ring size, the number of rings and in order of increasing number of heteroatoms. The heteroatoms have been arranged in the following sequence $\mathrm{N}, \mathrm{O}, \mathrm{S}$ and other elements. The overall style of heterocycles arrangement follows that used in Chemical Abstracts. Also, the naming of the heterocycles follows generally the practices of IUPAC and Chemical Abstracts.

\section{Heteroannulation}

\subsection{Heteroannulation of monoheterocycles}

2.1.1. Imidazolethiones. Reaction of $\mathrm{N}$-aryl 2-oxo-alkanehydrazonoyl halides with imidazoline-2(1H)-thione 9 in ethanolic triethylamine solution yielded the arylazo derivatives of imidazo[2,1-b]thiazole $\mathbf{1 0}$ via the thiohydrazonate (Scheme 3). ${ }^{14}$ Similar reaction of 9 with ethyl ( $N$-arylhydrazono) chloroacetate yielded the hydrazone derivative 11 (Scheme 3). ${ }^{14}$ 


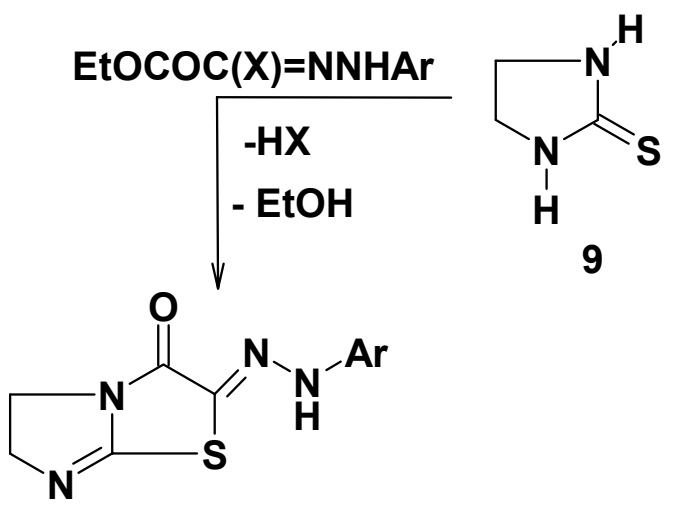

11

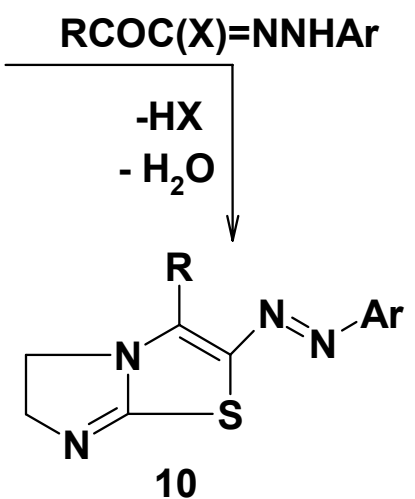

10

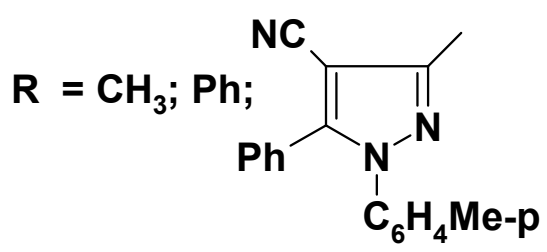

\section{Scheme 3}

Treatment of 4,5-diphenyl imidazoline-2(3H)-thione 12 with hydrazonoyl halides having no $\alpha$-oxo group in chloroform in the presence of triethylamine was reported to give the respective imidazo[2,1-c][1,2,4]triazole derivatives 13 directly (Scheme 4). ${ }^{7,15}$

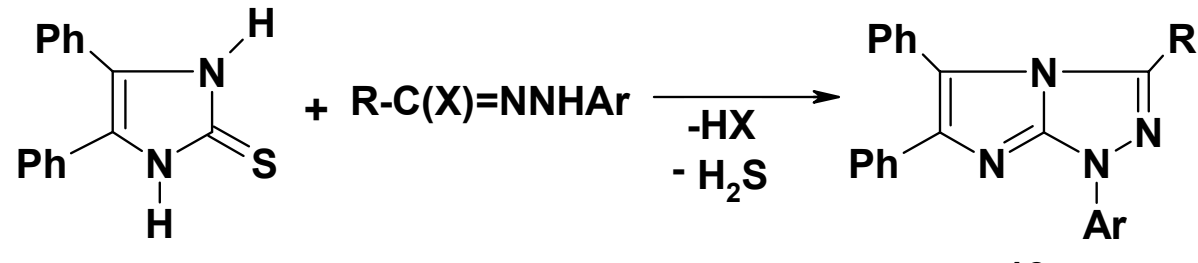

12

$$
\text { R = Ph, 2-thienyl, 2-furyl }
$$

\section{Scheme 4}

Also, imidazo[2,1-c][1,2,4]triazole derivatives $\mathbf{1 6}$ were obtained via reaction of 4arylhydrazono-2-methylthio-imidazolin-5(1H)-one 15 with various hydrazonoyl halide in ethanol in the presence of sodium ethoxide at room temperature (Scheme 5). ${ }^{16}$ 
<smiles>CCCCCN=C1N=C(SC)NC1=O</smiles>

i $\uparrow$

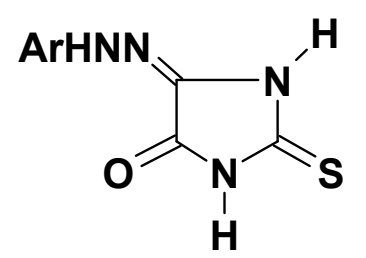<smiles>[R]C1=NN([Al])C2=NC(=O)/C(=N\N)N12</smiles>

16

14

\section{Scheme 5}

Very recently, it was reported that reaction of N-aryl-2-oxohydrazonoyl chlorides with 1amino-4-phenylimidazoline-2-thione $\mathbf{1 7}$ in ethanol in the presence of sodium ethoxide at room temperature afforded the respective 2-arylazo- $4 \mathrm{H}$-imidazo[2,1-b][1,3,4]thiadiazines $\mathbf{1 8}$ (Scheme 6). ${ }^{17}$ This finding indicates that the initially formed thiohydrazonates undergo in situ dehydrative cyclization as soon as they are formed to give $\mathbf{1 8}$ as end products.

$$
\begin{aligned}
& \text { i }=\mathrm{KOH} / \mathrm{EtOH} / \mathrm{Mel} \\
& \mathrm{ii}=\mathrm{EtONa} / \mathrm{EtOH} \\
& \mathrm{R}=\mathrm{Ph}, \mathrm{Ac}, \mathrm{EtOCO}
\end{aligned}
$$<smiles>CCON=CC(=O)NN=C(Cl)Cl</smiles>

17<smiles>[R]C1=NN2C=C(c3ccccc3)NC2S/C1=N/N[Ga]</smiles>

$\mathrm{R}: \mathrm{A}, \mathrm{Me} ; \mathrm{B}, \mathrm{Ph} ; \mathrm{C}, 2$-thienyl

$\mathrm{Ar}=\mathrm{XC}_{6} \mathrm{H}_{4}$

18

$\mathrm{X}$ : a,4-MeO; b, 4-Me; c, H; d, 4-Cl; e, 3-Cl;

f, 3-NO ${ }_{2} ; \mathrm{g}, 4-\mathrm{NO}_{2} ; \mathrm{h}, 4-\mathrm{COOEt} ; \mathrm{i}, 4-\mathrm{CN}$

\section{Scheme 6}

2.1.2. 1,2,4-Triazolethiones. Reaction of 5-phenyl-1,2,4-triazole-3(2H)-thione 19 with various hydrazonoyl chlorides gave the thiohydrazides 20, which were converted into 1,3,5- 
trisubstituted-1,2,4-triazolo[3,4-c][1,2,4]triazoles $\mathbf{2 1}$ by treatment with phosphorus oxychloride. $^{18-20}$ The latter products 21 were also prepared by reaction of 5-methylthio-3-phenyl$4 H$-1,2,4-triazole 22 with hydrazonoyl chloride (Scheme 7). ${ }^{18-20}$

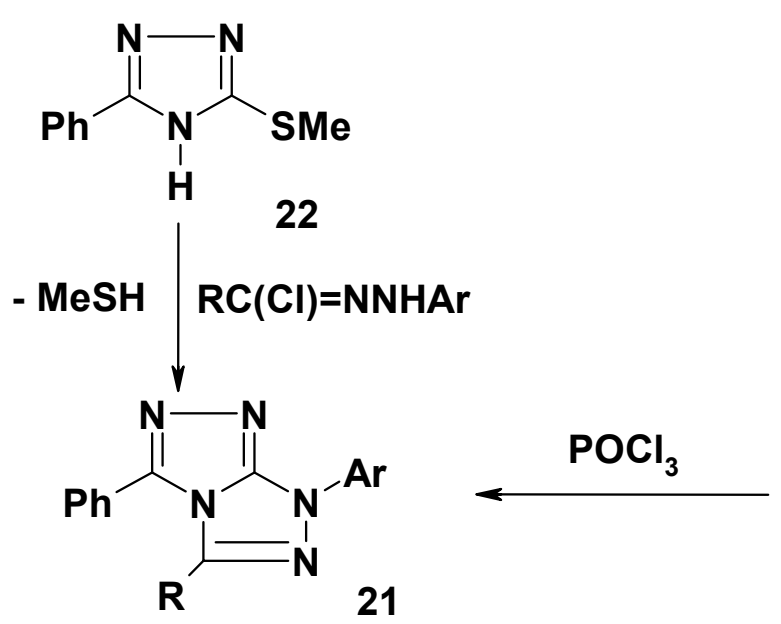<smiles>S=c1[nH]nc(-c2ccccc2)[nH]1</smiles>

19

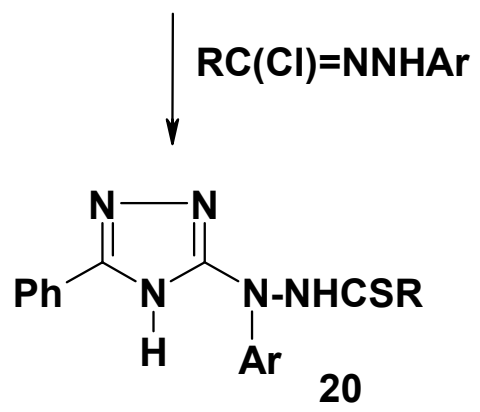

\section{Scheme 7}

Similar reaction of bis-hydrazonoyl chloride 23 with 3-methylthio-5-phenyl-4H-1,2,4triazole $\mathbf{2 4}$ was reported to give 3,3'-bis(1,2,4-triazolo[3,4-c][1,2,4]triazole derivative 25 (Scheme 8). ${ }^{21}$<smiles>CSc1nnc(-c2ccccc2)[nH]1</smiles>

24<smiles></smiles>

\section{Scheme 8}

However, reaction of the same bis-hydrazonoyl chloride 23 with 5-phenyl-1,2,4-triazole3(2H)-thione 19 was reported to give 5,6-bis(phenylhydrazono)-2-phenylthiazolo[3,2b] $[1,2,4]$ triazole 26 (Scheme 9). ${ }^{21}$ 


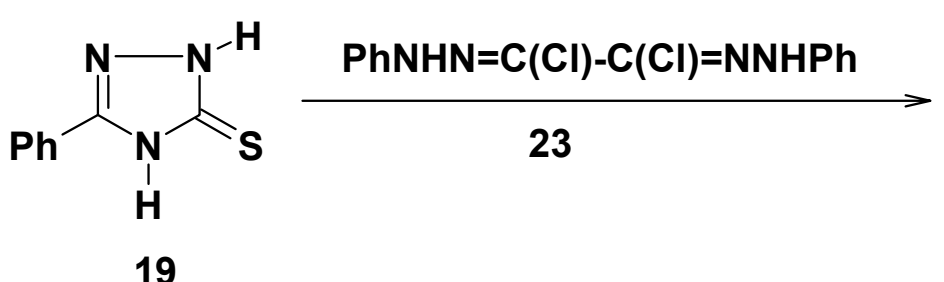

19

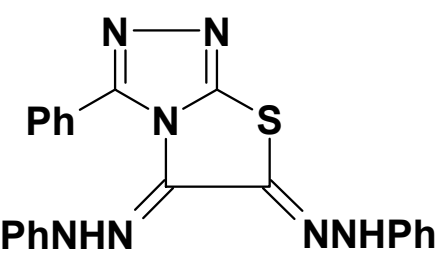

26

\section{Scheme 9}

Reaction of 4-amino-5-phenyl-1,2,4-triazole-3(2H)-thione 27 with 2-aryl-2oxoethanehydrazonoyl bromides in ethanol in the presence of sodium ethoxide was reported by Shawali et al. $^{22,23}$ to afford the respective thiohydrazonates 28a-g (Scheme 10). Similar reaction of 27 with the hydrazonoyl bromide having electron-withdrawing substituents in the $\mathrm{N}$-aryl moiety directly afforded, however, the respective 7-arylhydrazono-3,6-diaryl[1,2,4]triazolo[3,4b][1,3,4]thiadiazines $\mathbf{2 9} \mathbf{h}-\mathbf{j}$, probably via in situ dehydrative cyclization of the initially formed thiohydrazonates $\mathbf{2 8 h}-\mathbf{j} .{ }^{22,23}$ The thiohydrazonates $\mathbf{2 8 a - g}$ were converted into the respective triazolothiadiazines $\mathbf{2 9} \mathbf{a - g}$ by treatment with acetic acid (Scheme 10). ${ }^{22}$
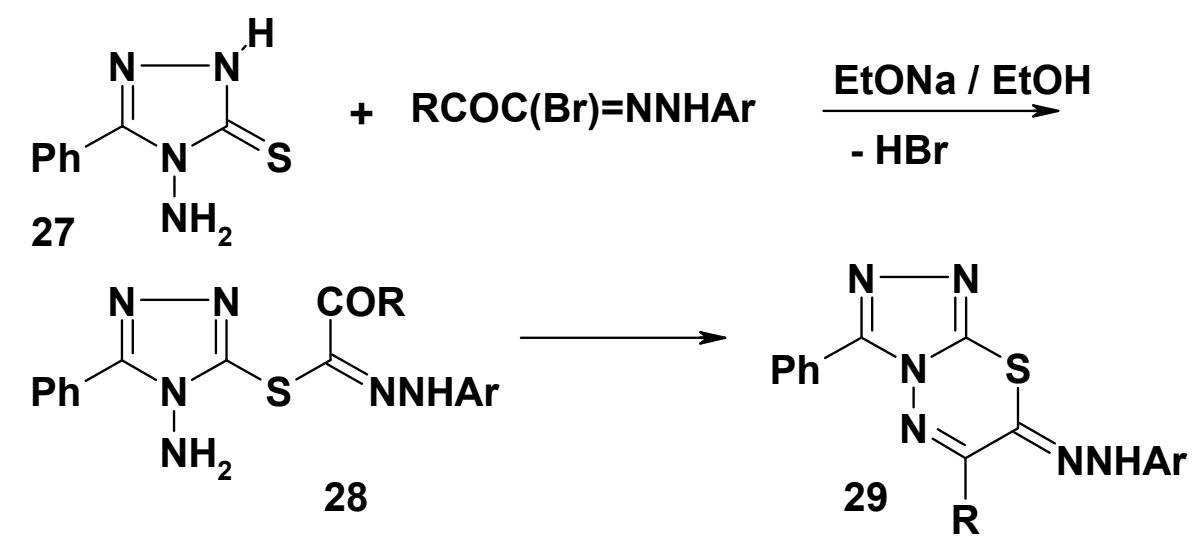

$$
\begin{aligned}
& \mathrm{Ar}=\mathrm{XC}_{6} \mathrm{H}_{4} \text { : a, 4-MeO; b, 4-Me; c, 3-Me; d, H; e, 4-Cl; } \\
& \text { f, 3-Cl; g, 4-NO } \mathrm{N}_{2} \text {; h, 4-MeCO; i, 4-EtOCO; j, 4-NO } \\
& R=\text { 2-naphthyl }
\end{aligned}
$$

\section{Scheme 10}

Similarly, several other series of 7-arylhydrazono-7H-3-heteroaryl-triazolo[3,4b] $[1,3,4]$ thiadiazin- $6(5 H)$-ones $\mathbf{3 1}$ and $\mathbf{3 2}$ were prepared via reaction of 4-amino-5-heteroaryl$[1,2,4]$-triazole-3(2H)-thiones 30 with ethyl arylhydrazonochloroacetate and $N$-aryl-2-oxoalkane hydrazonoyl halides, respectively (Scheme 11). ${ }^{24,25}$ 

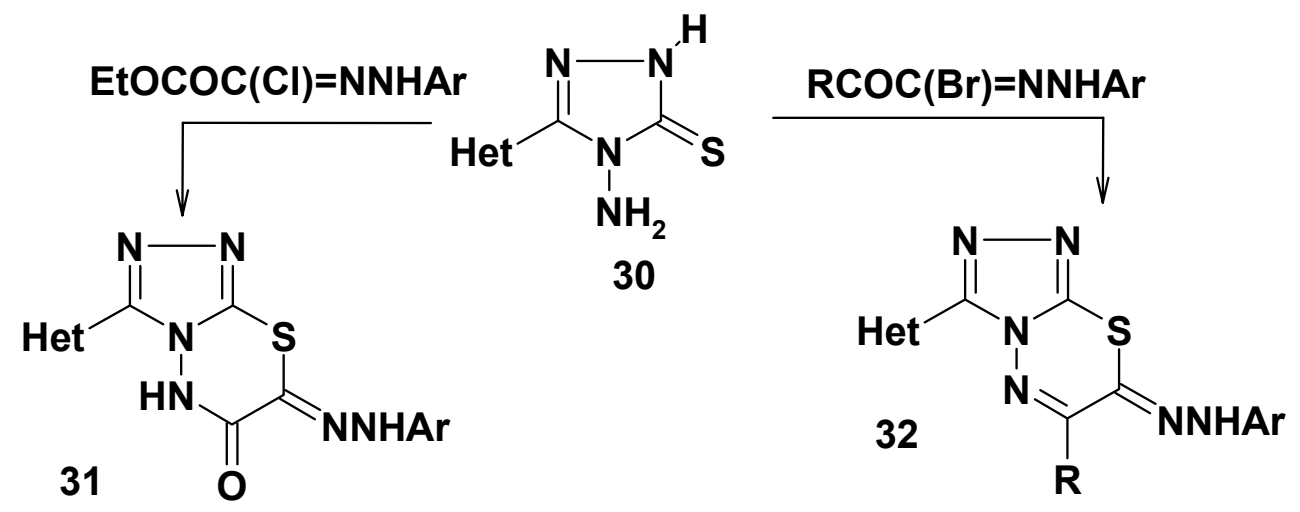

Het : A,<smiles>Cc1[nH]c2c(c1C)CCCC2</smiles>

$\mathbf{R}=\mathbf{M e}, \mathbf{P h}$
B,<smiles>Cc1oc2c(c1C)CCCC2</smiles>

\section{Scheme 11}

Furthermore, 1,2-bis(7-arylhydrazono-7H-[1,2,4]triazolo-[3,4-b][1,3,4]-thiadi- azin-3yl)ethanes 34 were prepared by reaction of 1,2-bis(4-amino-3-thioxo-2 $H$-[1,2,4]triazol-5yl)ethane 33 with $N$-aryl 2-oxopropanehydrazonoyl chlorides (Scheme 12). ${ }^{26}$

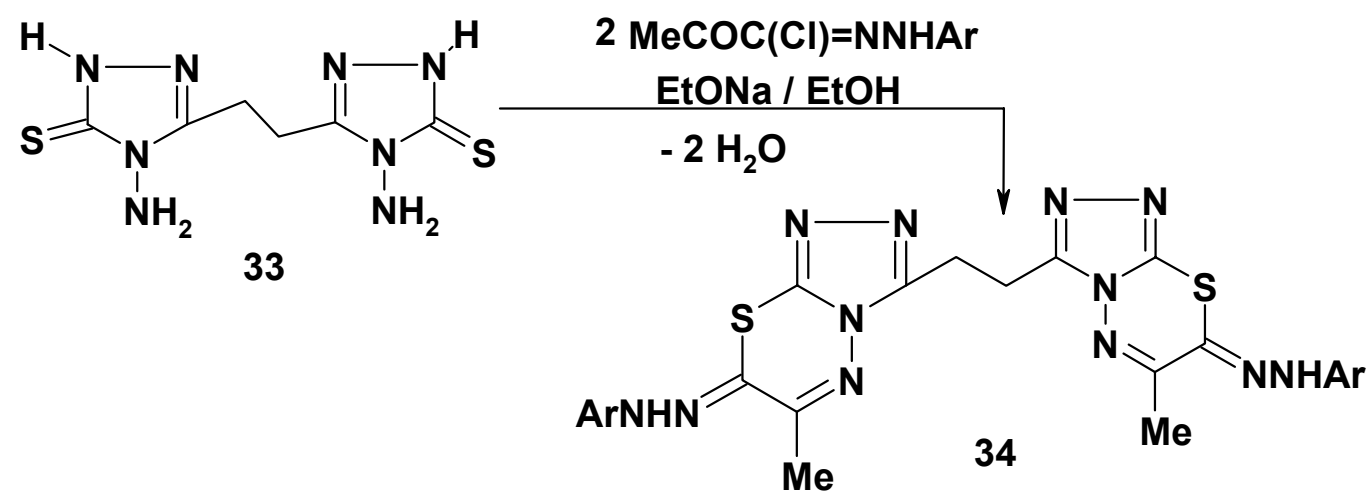

\section{Scheme 12}

2.1.3. Pyrmidinethiones. Hydrazonoyl halides reacted with 2-pyrimidinethione $\mathbf{3 5}$ in chloroform in the presence of triethylamine and yielded the corresponding $1 \mathrm{H,5H}$ $[1,2,4]$ triazolo[4,3-a]pyrimidine derivatives 36 (Scheme 13). ${ }^{27-32}$ 


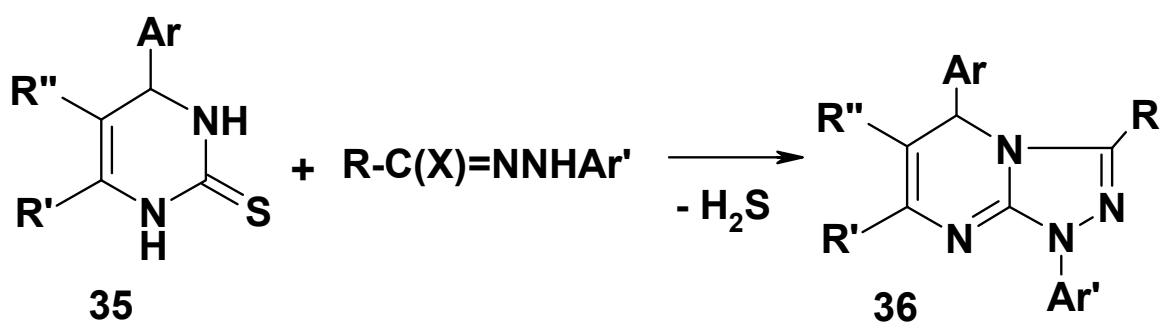

R / X : Ph / Cl; MeOCO / Cl; EtOCO / Cl; PhNHCO / Cl; Ac / Cl;

PhCO / Br; 2-thenoyl / Br;

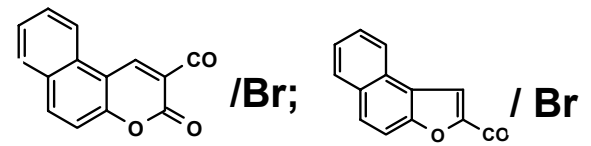

$\mathrm{Ar}^{\prime}=\mathrm{C}_{6} \mathrm{H}_{5} ; 4-\mathrm{MeC}_{6} \mathrm{H}_{4} ; 4-\mathrm{MeOC}_{6} \mathrm{H}_{4}$

$\mathrm{Ar}=\mathrm{XC}_{6} \mathrm{H}_{4} / \mathrm{MeOCO}$, EtOCO, 1-naphthyl, 2-naphthyl

$\mathrm{R}^{\prime}$ = Me, 2-thienyl, Ph, 2-naph hyl

$\mathbf{R}^{\prime \prime}=\mathrm{EtOCO}, \mathrm{MeOCO}, \mathrm{Me}, \mathrm{H}$

Scheme 13

Reactions of hydrazonoyl halides with 6-substituted-2-thiouracils $\mathbf{3 7 A}^{33-37}$ and 5,6disubstituted-2-thiouracils $\mathbf{3 7}^{29,34,38-40}$ as well as their 2-methylthio derivatives $\mathbf{3 8}$ were reported to be regioselective and afforded the respective 1,2,4-triazolo[4,3- $a$ ]pyrimidinone derivatives 39 (Scheme 14).<smiles>[R][AsH2]c1nc([Z])c([Y])c(=O)[nH]1</smiles>

$37, R^{\prime}=H^{\prime}$

38, $R^{\prime}=\mathrm{Me}$<smiles>[Z]c1nc2n([Ga])nc([R])n2c(=O)c1[Y]</smiles>

39

$$
\begin{gathered}
\text { R = Ph, PhNHCO, EtOCO,PhCO,MeOCO, AC, 2-Thenoyl, } \\
\text { 2-Naphthoyl, Ar-N=N- } \\
\text { Y = H, NC, EtOCO, MeOCO, PhN=N } \\
\text { Z = Me, Ph, 2-thienyl, } \mathrm{H}_{2} \mathrm{~N}, \mathrm{HO}
\end{gathered}
$$

Scheme 14 
The involvement of the thiohydrazonates and thiohydrazides as intermediate in the reactions of hydrazonoyl halides with 2-thiouracils 37 was evidenced by alternate synthesis of 39. ${ }^{37}$ Thus, treatment of 2-thiouracil derivative $\mathbf{3 7}$ with active 3-chloromethylene compounds $\mathbf{4 0}$ afforded the S-alkylated products 41, which yielded upon coupling with diazonium salts the thiohydrazonates 42 via Japp-Klingeman ${ }^{34}$ reaction. The latter esters, upon treatment with sodium ethoxide in ethanol underwent Chapman-like rearrangement ${ }^{7,9}$ to give the corresponding thiohydrazides $\mathbf{4 3}$ which cyclized in situ to yield the respective 1,2,4-triazolo[4,3-a]pyrimidinones 39 (Scheme 15).
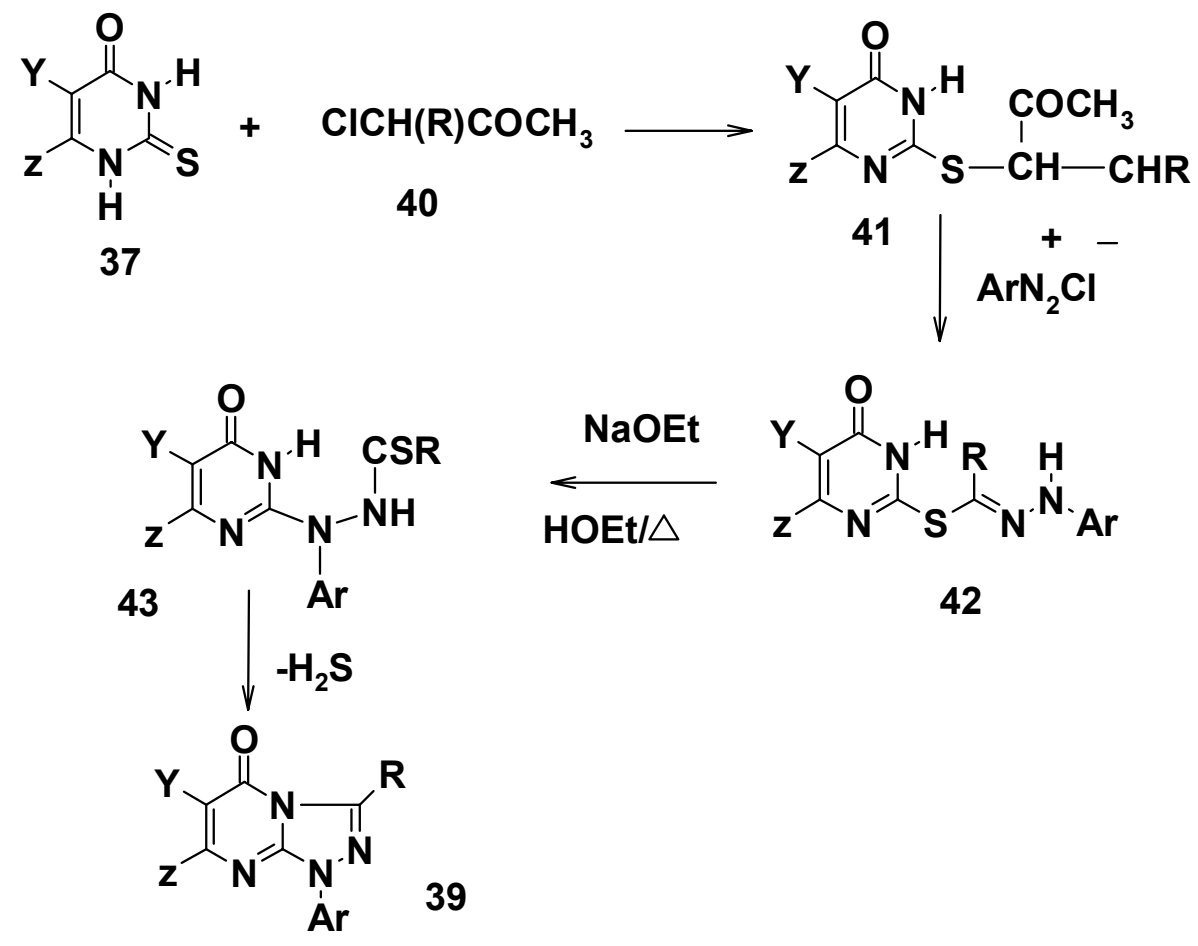

\section{Scheme 15}

Reaction of 6-amino-2-thiouracil 37A with $N$-phenyl benzenecarbohydrazonoyl chloride in dioxane in the presence of triethylamine under reflux yielded 39 (Scheme 16). The other isomeric structure 44 was discarded on the basis of the IR and ${ }^{13} \mathrm{C}$ NMR evidences. ${ }^{35}$ When compound 39 was refluxed with benzaldehyde in acetic acid, it yielded 44 (Scheme 16). ${ }^{36}$ 
<smiles>Nc1cc(=O)[nH]c(=S)n1-c1ccccc1</smiles>

\section{Scheme 16}

Bishydrazonoyl chloride $\mathbf{2 3}$ was reported to react regioselectively with 2-thiouracil $\mathbf{3 7 A}$ to give a mixture of 2,3-bis-(arylhydrazono)-thiazolo[3,2-a]pyrimidine-5-one 46 and 3,3'-bis-1,2,4triazolo[4,3-a]pyrimidin-5-one 47. However, reaction of the same bis-hydrazonoyl chloride with 2-methylthiouracil 38 afforded only 47 (Scheme 17). ${ }^{41}$

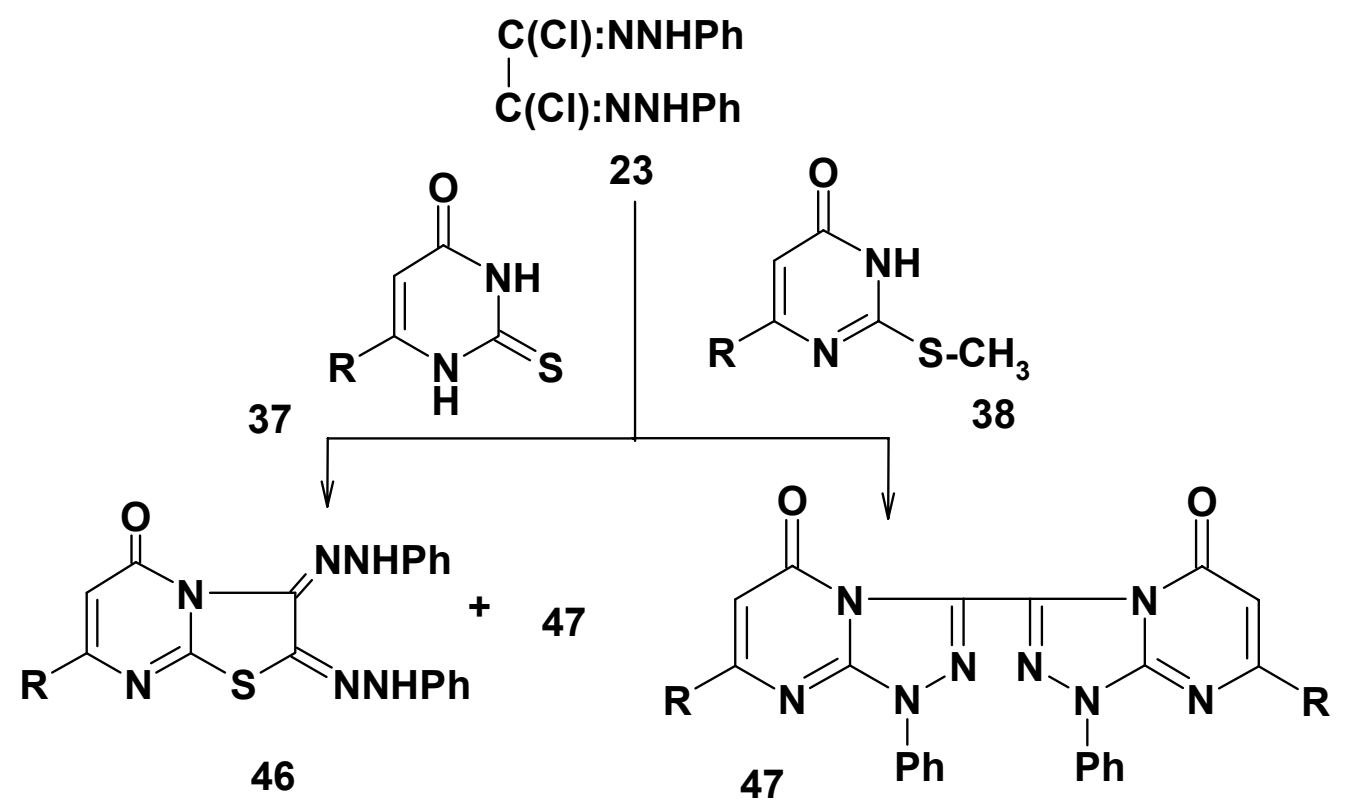

\section{Scheme 17}

Reactions of hydrazonoyl halides with either 3-amino-2,3-Dihydro-6-substituted-2thioxopyrimidin-4(3H)-ones $\mathbf{4 8}$ or 3-amino-6-substituted -2,3-dihydro-2-methylthio-4(3H)- 
pyrimidinone 49 were recently reported by Shawali et al ${ }^{42-44}$ to give the respective $4 \mathrm{H}-$ pyrimido[1,2-b][1,2,4,5]tetrazin-6-ones $\mathbf{5 0}$ (Scheme 18).

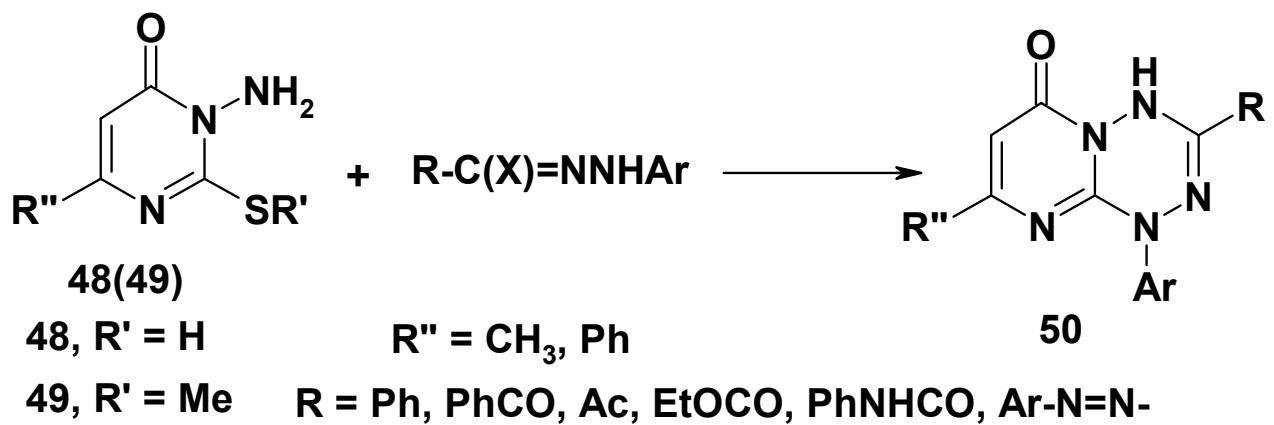

Scheme 18

2.1.4. 1,2,4-Triazine-5(4H)-thiones. $N, N$-Diphenyl ethane-bishydrazonoyl chloride 23 was reported to react with 2,3-dihydro-3-thioxo-1,2,4-triazin-5(4H)-one $\mathbf{5 1}$ and its 3-methylthio derivative $\mathbf{5 2}$ to give 2,3-bis(phenylhydrazono)thiazolo-[3,2-b][1,2,4]triazin-7-one 52 and 3,3'bis(1,2,4-triazolo[4,3-b][1,2,4] triazines) 54 (Schemes 19 and 20) respectively. ${ }^{21}$
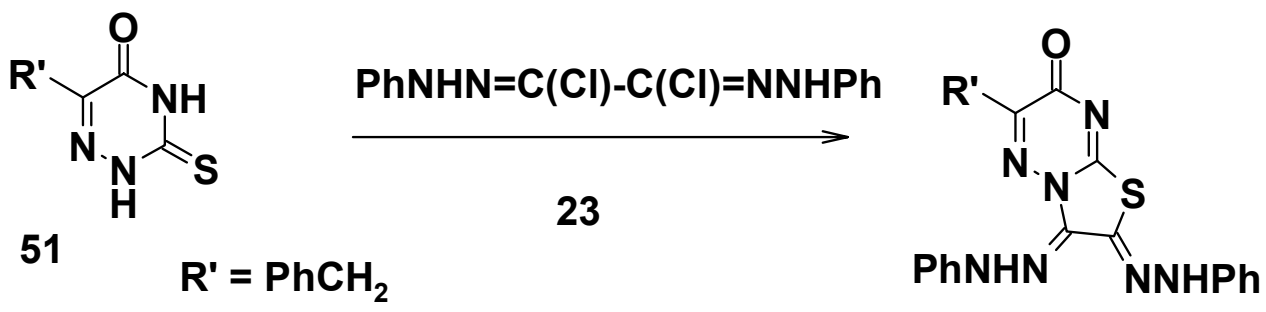

52

Scheme 19<smiles>[R]c1nnc(SC)[nH]c1=O</smiles>

53
$\mathrm{PhNHN}=\mathrm{C}(\mathrm{Cl})-\mathrm{C}(\mathrm{Cl})=\mathrm{NNHPh}$

23

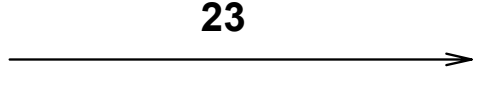

$$
\mathbf{R}^{\prime}=\mathrm{PhCH}_{2}
$$<smiles></smiles>

Scheme 20 
Reactions of hydrazonoyl halides with either 6-substituted 3-thioxo-1,2,4-triazin-5(2H)-ones $\mathbf{5 1} \mathbf{1}^{45}$ or 6-substituted-3-methylthio-1,2,4-triazin-5(4H)-one $\mathbf{5 3}^{46}$ were reported to give in both cases the respective 1,2,4-triazolo[4,3-b][1,2,4]triazin-7(1H)-ones $\mathbf{5 5}$ (Scheme 21). The structure of the latter products and the regiochemistry leading to them was confirmed by Shawali et al. ${ }^{46}$ via their alternate synthesis. ${ }^{46}$ Thus, treatment of 2-chloro-3-oxobutanilide and ethyl 2-chloro-3oxobutanoate each with 2,3-dihydro-3-thioxo-1,2,4-triazin-5(4H)-one 51 afforded the respective active (1,2,4-triazin-3-yl)thio methylene compounds 56. Reaction of the latter with benzenediazonium chloride in ethanol in the presence of sodium acetate furnished the azo compounds 57, which yielded $[1,2,4]$ triazolo[4,3-b][1,2,4]triazin-7(1H)-ones $55(\mathrm{Ar}=\mathrm{Ph})$ upon treatment with sodium ethoxide in ethanol (Scheme 22). ${ }^{46}$

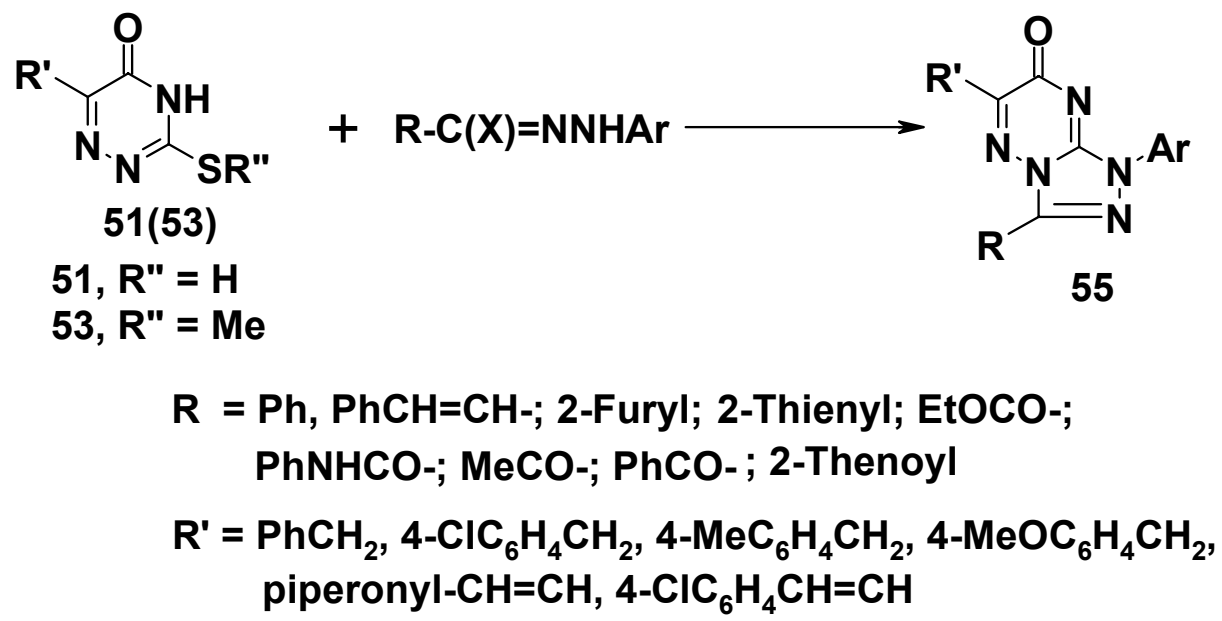

Scheme 21<smiles></smiles><smiles>[R]c1nnc(SC([R])([R])C(C)=O)[nH]c1=O</smiles><smiles>[R]c1nn2c([R])nn(-c3ccccc3)c2nc1=O</smiles>

Scheme 22 
Very recently Shawali et al. ${ }^{47}$ reported that reaction of hydrazonoyl halides with either 4amino-2,3-dihydro-6-substituted-3-thioxo-[1,2,4]triazin-5(2H)-ones $\mathbf{5 8 a , b}$ or 4-amino-2,3dihydro-3-methylthio-6-substituted-[1,2,4]triazin-5(4H)-ones 59a,b gave the respective $[1,2,4]$ triazino[4,3-b][1,2,4,5]tetrazine derivatives 60 (Scheme 23). Similar reactions of 58 and 59 each with 3-chloroformazans were also found to give the respective 3-arylazo derivatives 60 $(\mathrm{R} "=\mathrm{Ar}-\mathrm{N}=\mathrm{N}-)^{44}($ Scheme 23$)$.

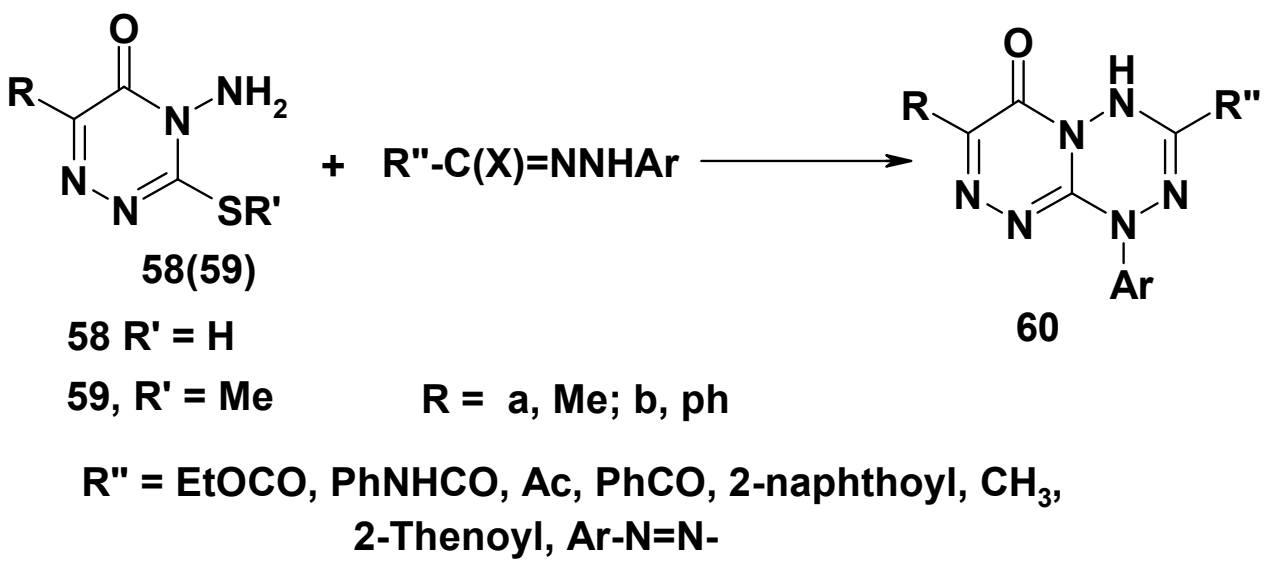

Scheme 23

2.1.5. 1,2,4-Triazepinethiones. The reaction of $N$-aryl- $C$-ethoxycarbonylnitrilimines with $[1,2,4]$ triazepine-3,5-dithiones $\mathbf{6 1}$ was reported to yield the respective $[1,2,4]$-triazolo[4,3d] $[1,2,4]$ triazepines 62 (Scheme 24). ${ }^{48}$ The reaction was said to be completely peri and regioselective. The prefered orientation was predicted correctly by AM1 calculations.

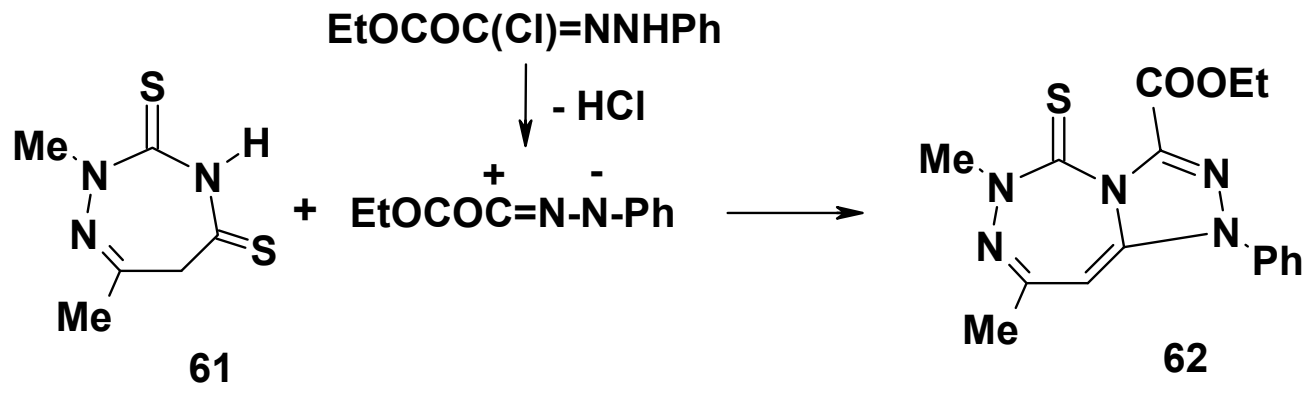

Scheme 24 


\subsection{Heteroannulation of biheterocycles}

2.2.1. Benzimidazolethiones. When benzimidazole-2-thiol 63 was refluxed with hydrazonoyl halides in chloroform in the presence of triethylamine, it afforded the respective 1,2,4triazolo[4,3-a]benzimidazoles 64 (Scheme 25). ${ }^{15}$<smiles>Sc1nc2ccccc2[nH]1</smiles>

63

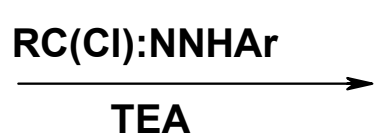

TEA

R : Ph, 2-thienyl, 2-furyl<smiles>[R]c1nn([Al])c2nc3ccccc3n12</smiles>

64

\section{Scheme 25}

The reaction of benzimidazole-2-thiol 63 with ethyl ( $N$-arylhydrazono)chloroacetate and 2phenylamino-2-oxoethane-hydrazonoyl chloride in the presence of base catalyst yielded the corresponding thiohydrazonate esters $\mathbf{6 5 a}$ and $\mathbf{6 5} \mathbf{b}$, respectively. ${ }^{14}$ Acid treatment of the latter products resulted in their cyclization to give thiazolo[3,2-a]benzimidazol-3-one $\mathbf{6 6}$ (Scheme 26). ${ }^{14}$

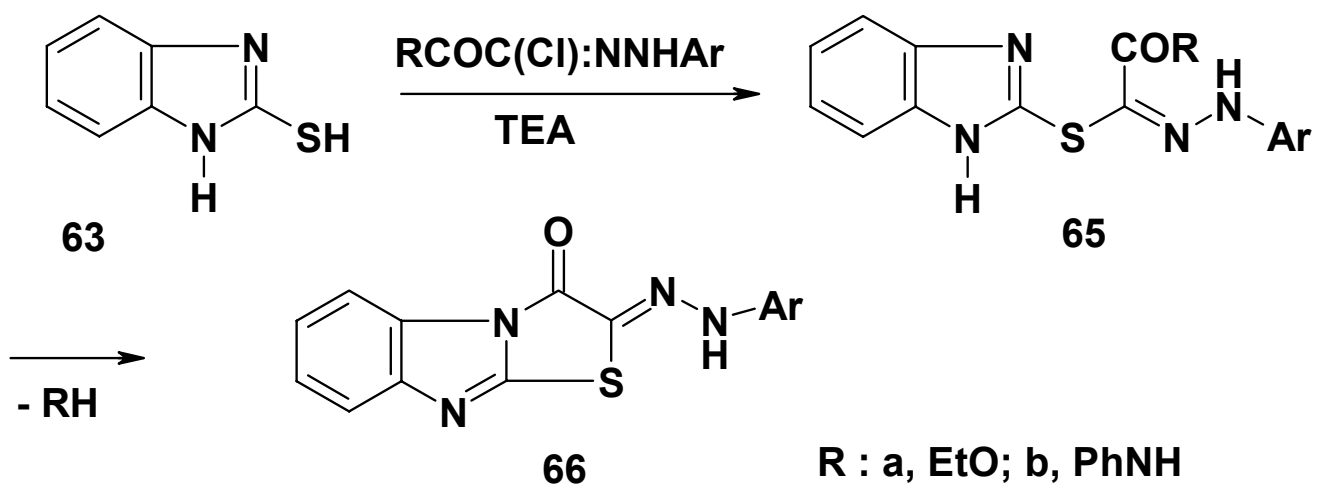

\section{Scheme 26}

Similar reaction of 2-oxopropanehydrazonoyl chloride, ${ }^{14}$ 2-oxo-2-(pyrazol-3yl)ethanehydrazonoyl bromide, ${ }^{14}$ and $N$-phenyl 2-(2-phenyl-4-methylthiazol-5-yl)-2oxoethanehydrazonoyl bromide ${ }^{50}$ each with benzimidazole-2-thione 63 afforded the respective thiohydrazonate esters $\mathbf{6 5}$ that cyclized upon heating to give the corresponding 2arylazothiazolo[3,2-a]benzimidazoles 67 (Scheme 27). 


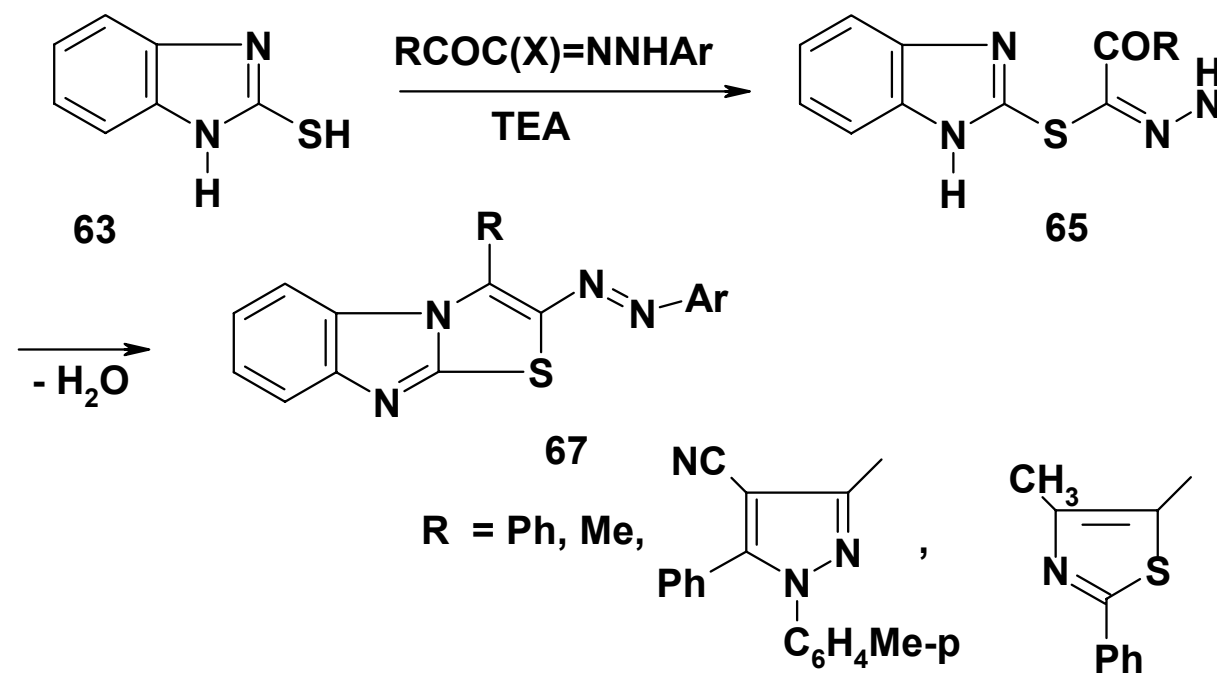

\section{Scheme 27}

2,3-Bis(phenylhydrazono)thiazolo[3,2-a]benzimidazoles 68 were obtained by reaction of bishydrazonoyl chloride 23 with benzimidazole-2-thiol 63 (Scheme 28). ${ }^{21}$ Treatment of bis(phenylhydrazone) $\mathbf{6 8}$ with lead(IV) tetracetate in DMF-acetonitrile mixture afforded the respective bis(phenylazo) derivative $69 .^{21}$

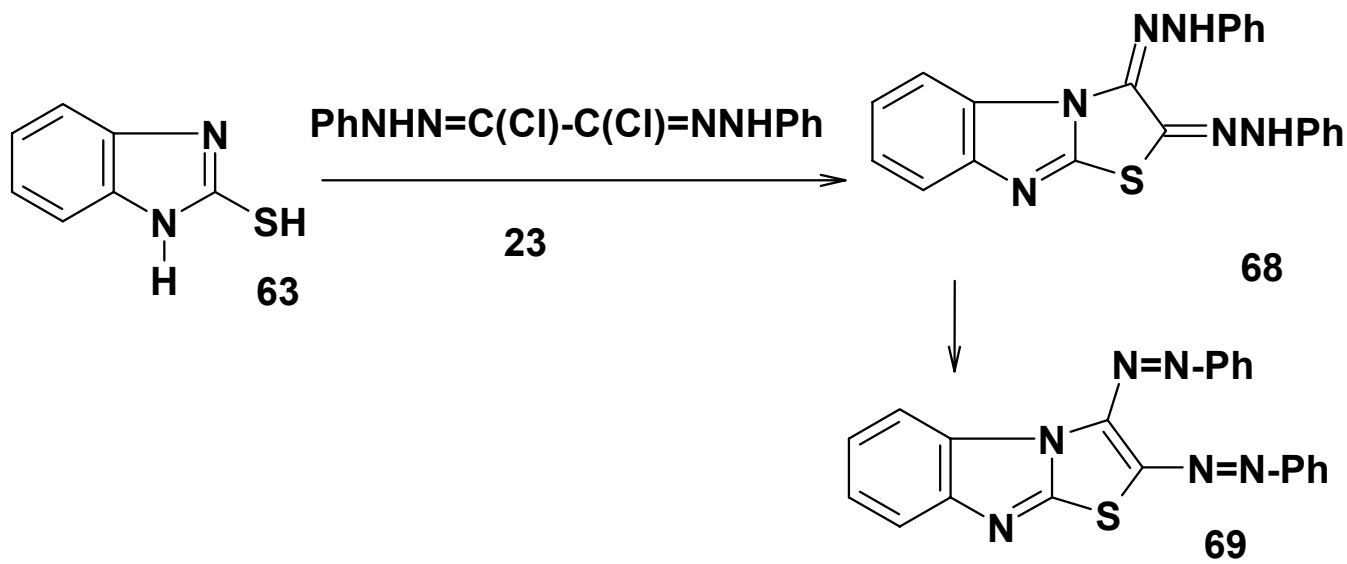

\section{Scheme 28}

Treatment of benzimidazole-2-thiol $\mathbf{6 3}$ with hydrazonoyl halides in refluxing chloroform in the presence of triethylamine was reported to give the respective 1,2,4-triazolo[4,3a]benzimidazole derivatives $\mathbf{7 1} .^{15,51,52}$ The latter product were also obtained by refluxing 2methylthiobenzimidazole $\mathbf{7 0}$ with hydrazonoyl halides in chloroform in the presence of triethylamine (Scheme 29). ${ }^{15,49,50,51,53}$ 


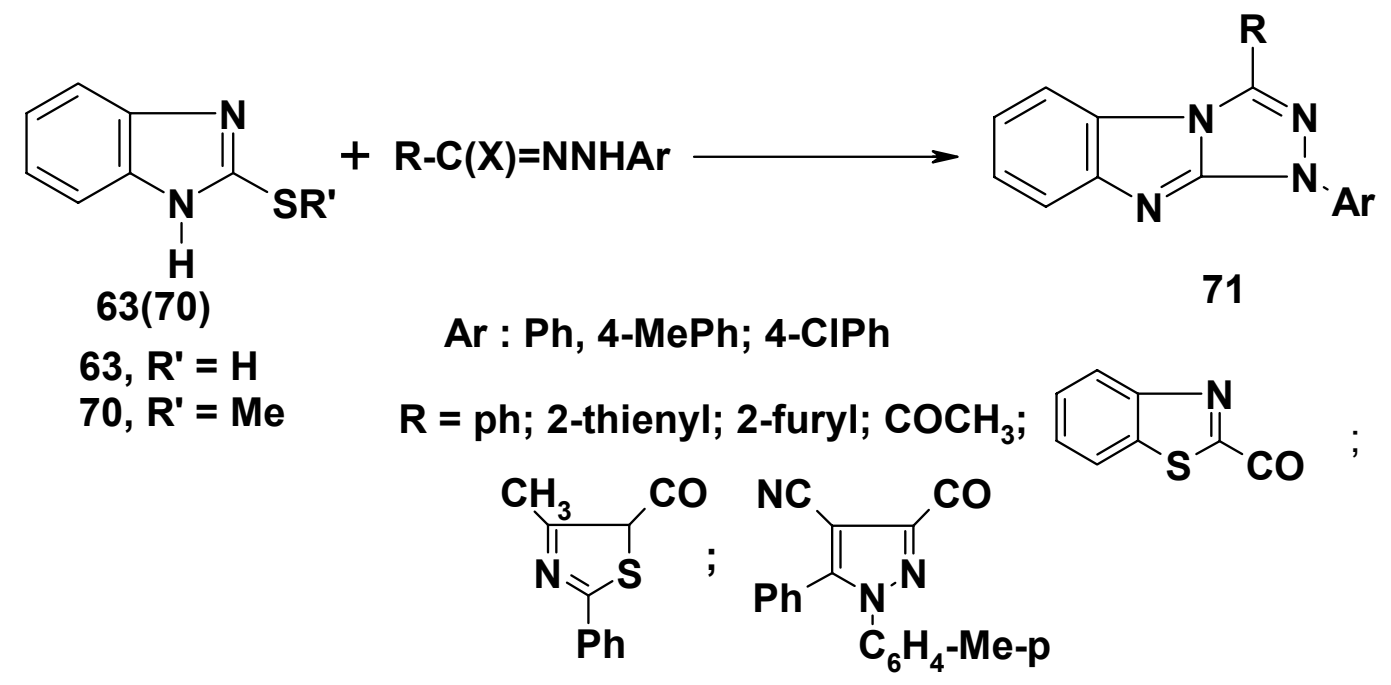

\section{Scheme 29}

The reaction of bishydrazonoyl chloride $\mathbf{2 3}$ with 2-methylthio-benzimidazole $\mathbf{7 0}$ was reported recently to give 3,3'-bis(1,2,4-triazolobenzimidazole) 72 (Scheme 30). ${ }^{21}$
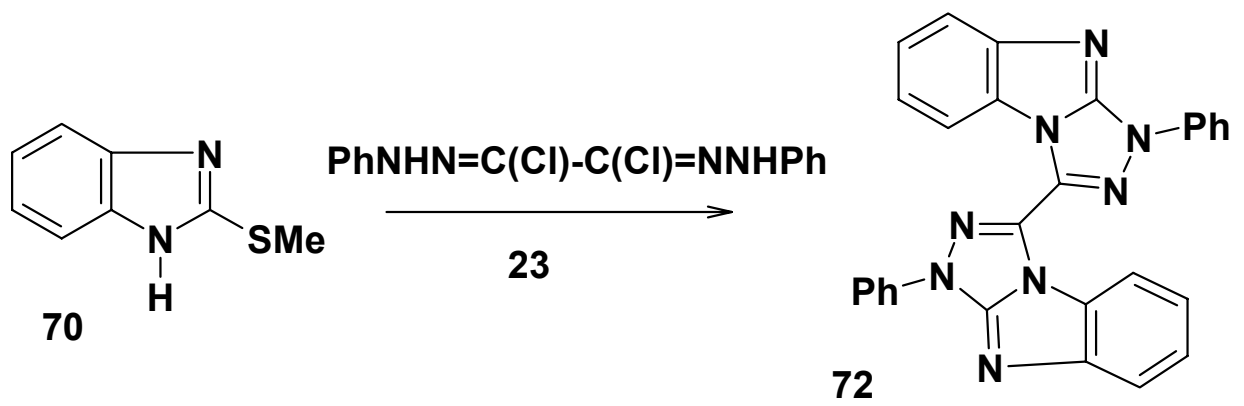

\section{Scheme 30}

2.2.2. Purinethiones. Recently Shawali et al. ${ }^{54}$ reported that reactions of hydrazonoyl halides with theophylline-8-thione $\mathbf{7 3}$ and 8-methylthiotheophylline $\mathbf{7 4}$ in refluxing pyridine yielded in both cases 1,3-disubstituted [1,2,4] triazolo[3,4-f]purine derivatives 75 (Scheme 31). The formation of the latter from $\mathbf{7 4}$ and hydrazonoyl halides was proposed to proceed via 1,3-dipolar cycloaddition of nitrilimines, derived by the action of pyridine on hydrazonoyl halides used, on the $\mathrm{C}=\mathrm{N}$ double bond to give the cycloadducts as intermediates which undergo in situ elimination of methanethiol to give $\mathbf{7 5}$ as end products (Scheme 31). However, the formation of 75 from 73 and hydrazonoyl halides was supposed to proceed via the formation of the thiohydrazonate esters which then undergo in situ two tandem reactions namely rearrangement 
into the thiohydrazides followed by cyclization of the latter with concurrent elimination of $\mathrm{H}_{2} \mathrm{~S}$ to afford 75 (Scheme 31). ${ }^{54}$

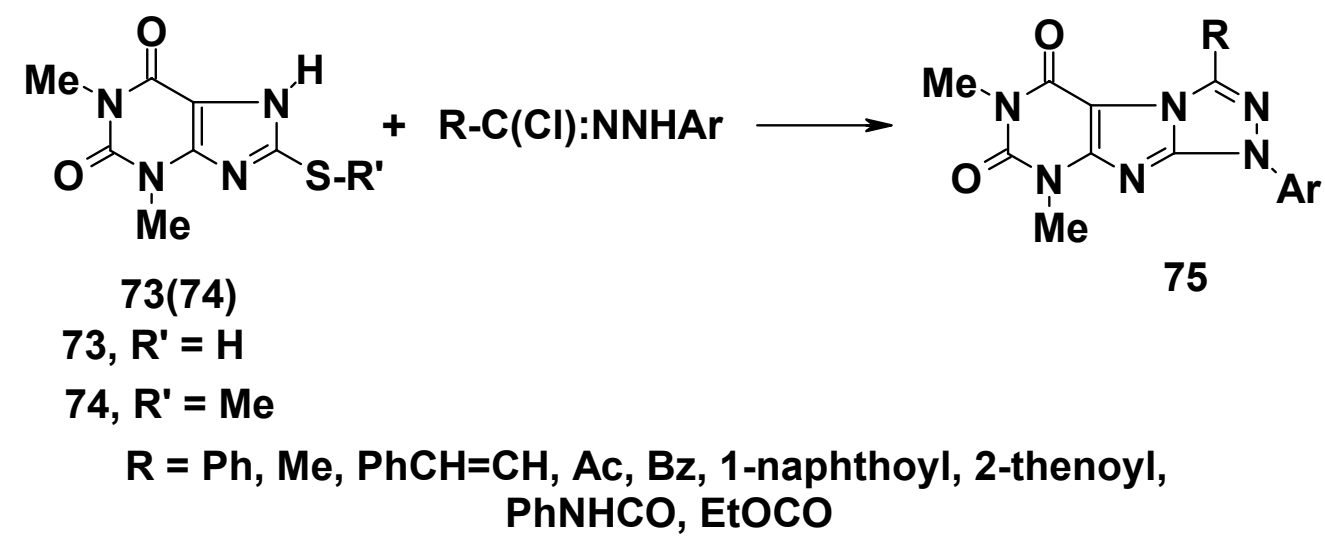

\section{Scheme 31}

2.2.3. Pyrazolo[3,4-d]pyrimidinethiones. Reaction of hydrazonoyl halides with 5-amino-1phenyl-6-thioxopyrazolo[3,4-d]pyrimidin-4-one 76A and its methylthio derivative 77B in refluxing dioxane in the presence of triethylamine was also reported by Shawali et $\mathrm{al}^{55}$ to afford pyrazolo[3,4- $d$ ]pyrimido[1,2-b][1,2,4,5] tetrazine derivatives 78. The mechanism of the studied reaction was discussed and the structures of the isolated products were evidenced by alternate synthesis depicted in Scheme $32 .^{55}$

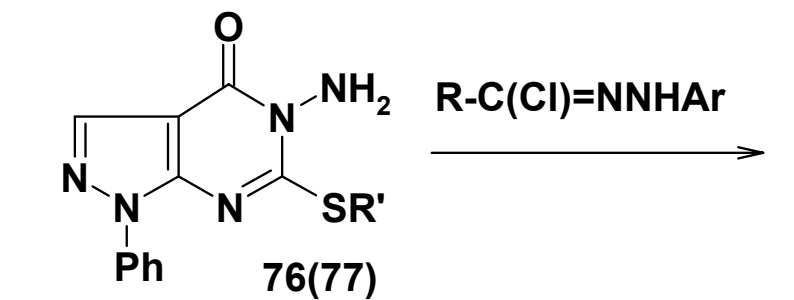<smiles>[R]C1=NN([Ga])c2nc3c(cnn3-c3ccccc3)c(=O)n2N1</smiles>

76, R' $=$ H
77, R' $=$ Me $\quad$ R : Ph; EtOCO; PhCO; Ac; PhNHCO<smiles>[R]C(=O)C(C)C(C)=O</smiles>

1) $\mathrm{ArN}_{2} \mathrm{Cl}$

2) EtONa / EtOH

Scheme 32 
2.2.4. Quinazolinethiones. Reaction of bis-hydrazonoyl chloride 23 with 2 -thioxoquinazolin4(1H)-one 80 afforded the bis-(phenylhydrazono)-thiazoloquinazoline derivative $\mathbf{8 1}$ (Scheme 33). ${ }^{41}$

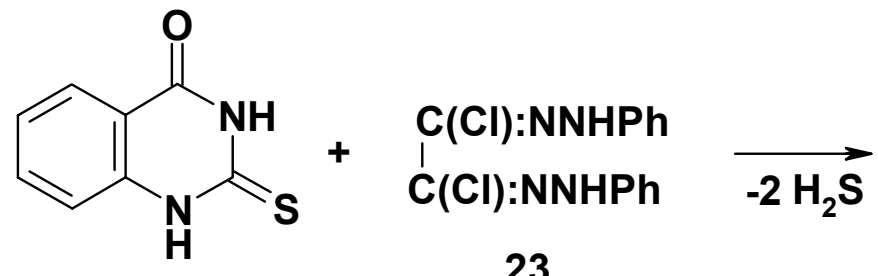

80<smiles>O=c1nc2n(c3ccccc13)C(=Nc1ccccc1)/C(=N/c1ccccc1)S2</smiles>

81

Scheme 33

Similar reaction of $\mathbf{8 0}$ with various hydrazonoyl halides in refluxing chloroform in the presence of triethylamine yielded 1,3-disubstituted 1,2,4-triazolo[4,3-a]quinazolin-5-one derivatives 82. The other regioisomers 83 were not produced (Scheme 34). ${ }^{56}$

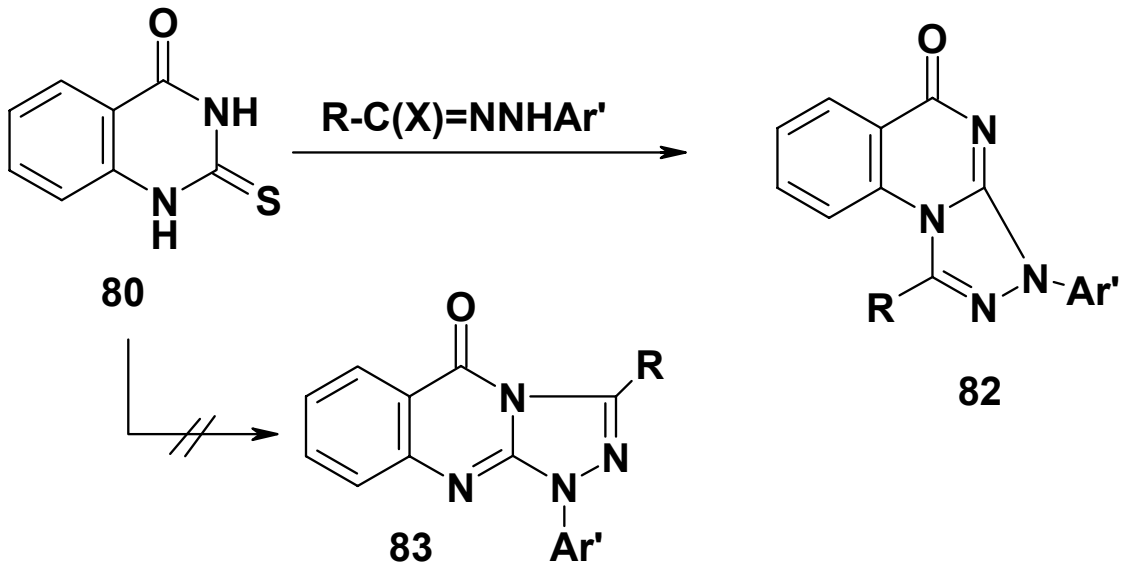

$\mathrm{R} / \mathrm{X}$ : Me / Br; Et / Br; $\mathrm{Ph} / \mathrm{Cl} ; \mathrm{PhCH}=\mathrm{CH}-/ \mathrm{Cl}$;

2-thienyl / Br; Ac / Cl; EtOCO / Cl; PhCO / Br; 2-thenoyl / Br;

$\mathrm{Ph} / \mathrm{Br}$; 2-naphthoyl / Br; 2-furyl / Br; PhNHCO / Cl

\section{Scheme 34}

Also, it was reported that reaction of hydrazonoyl halides with 3-amino-2-thioxoquinazolin4(1H)-one 84 afforded $4 H$-[1,2,4,5]-tetrazino[3,2-b]quinazolin-6-ones 86 (Scheme 35$){ }^{57}$ The latter products 86 were also obtained by reaction of 3 -amino-2-methylthioquinazolin-4(3H)-one 85 with the same series of hydrazonoyl halides (Scheme 35). ${ }^{57,58}$ 


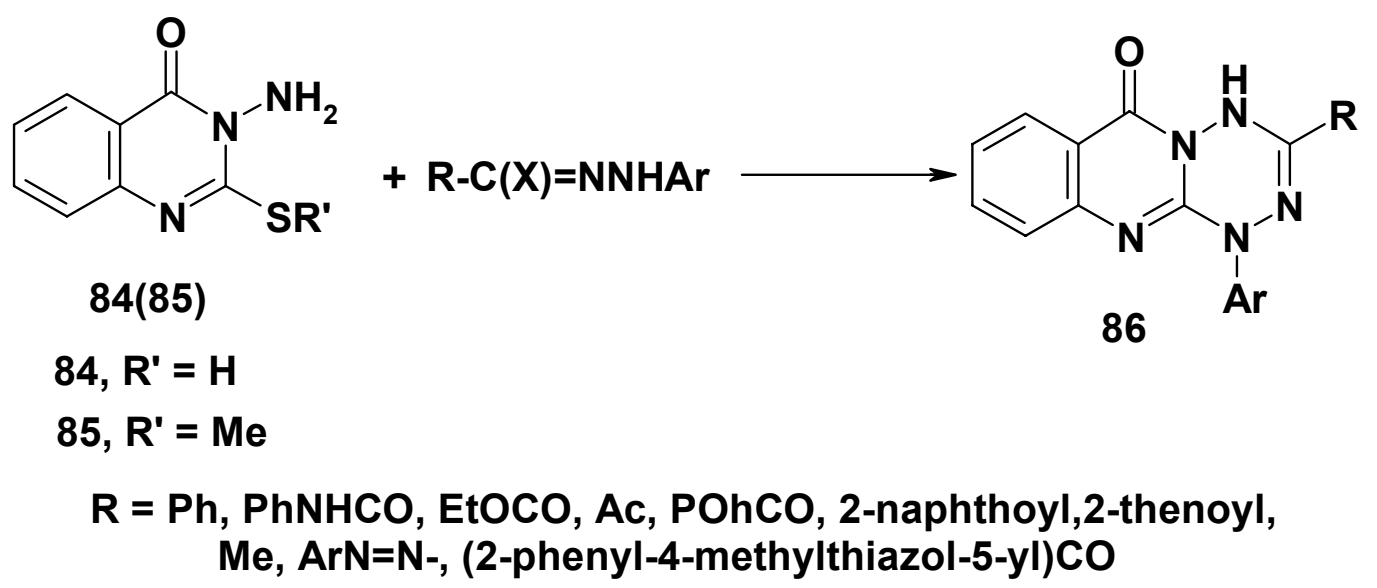

\section{Scheme 35}

2.2.5. Pyrido $[2,3-d]$ thiouracils. Recently, it was reported that treatment of pyridino[2,3- $d]-2-$ thiouracil $\mathbf{8 7}$ with hydarzonoyl chlorides in boiling chloroform in the presence of triethylamine yielded the corresponding pyridino[2,3- $d]$ triazolo[4,3-a]pyrimidin-5-one derivatives 88. The structure of the latter products $\mathbf{8 8}$ were established by their alternate synthesis via reaction of formamidine $\mathbf{8 9}$ with acetophenone in boiling acetic acid (Scheme 36). ${ }^{59,60}$ The involvement of the thiohydrazonate esters as intermediates in the studied reactions of $\mathbf{8 7}$ with hydrazonoyl halides was evidenced by alterenate synthesis of $\mathbf{8 8}$ via reaction of $\mathbf{8 7}$ with the appropriate active $\alpha$-chloromethylene compounds followed by coupling with diazotized aniline to give the respective coupling products. Treatment of the latter with ethanolic sodium ethoxide resulted in its Chapman-rearrangment ${ }^{7,9}$ to yield the respective thiohydrazides which cyclized in situ to give $\mathbf{8 8}$ as end products (Scheme 36). ${ }^{60}$ 


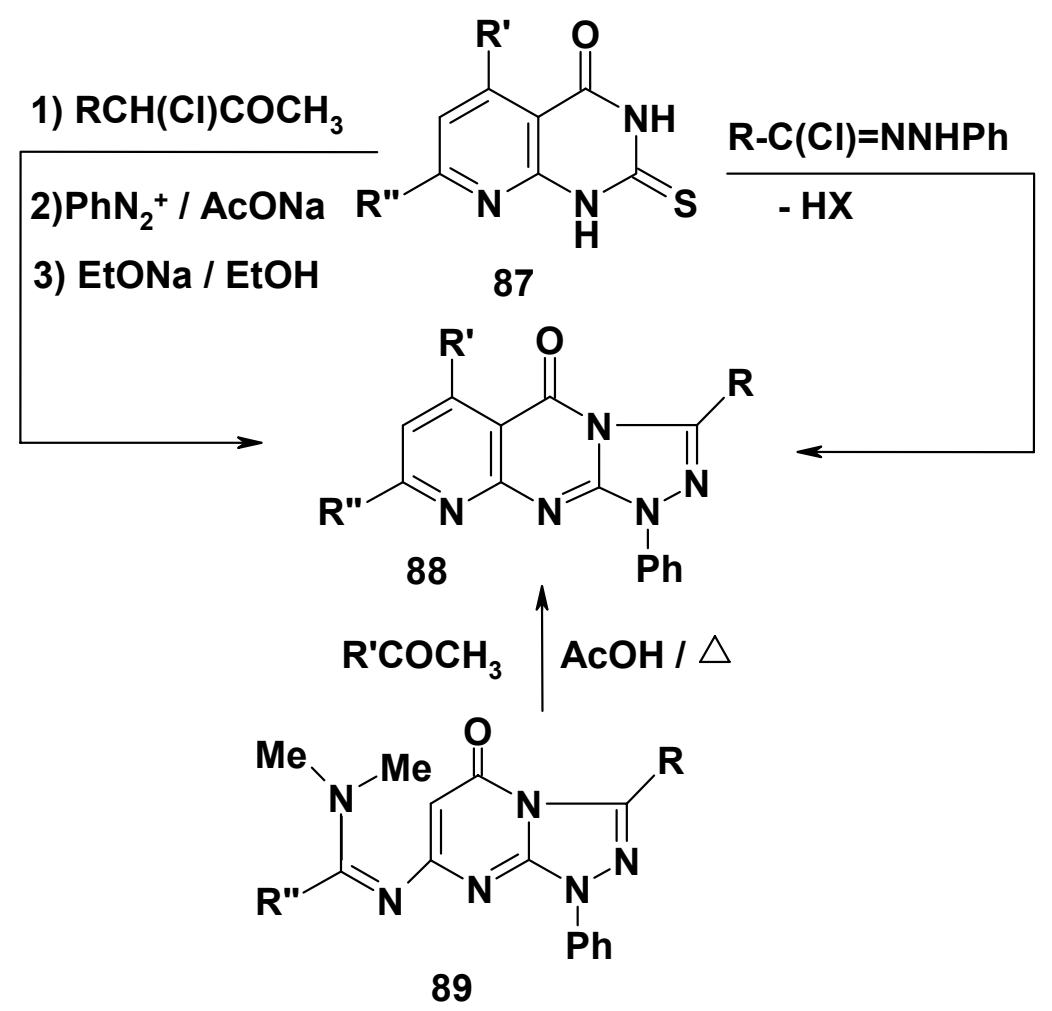

R : Ac, EtOCO, PhNHCO, PhCO, Ph

Ar : 4- $\mathrm{O}_{2} \mathrm{NC}_{6} \mathrm{H}_{4}$

R' : Ph; 2-thienyl

\section{Scheme 36}

2.2.6. Pteridinethiones. Reaction of 2-thioxopteridine-4(3H)-one derivatives 90 with hydrazonoyl halides in tetrahydrofuran in the presence of triethylamine under reflux afforded the respective 1,2,4-triazolo[3,4-b]pteridine derivatives 91 (Scheme 37). ${ }^{61}$ The structure of the latter products was established by X-ray analysis.<smiles>[R]c1nc2[nH]c(=S)[nH]c(=O)c2nc1[R]</smiles>

R : Ph; PhCH=CH-; EtOCO; PhCO; Ac

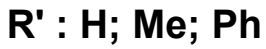

Scheme 37 
2.2.7.Quinoxalinethiones. Various 2,4-disubstituted-4H-1,3,4-thiadiazino[5,6- $b$ ] quinoxalines 93 were obtained by reaction of hydrazonoyl halides with 2-amino-3-quinoxalinethiol 92 in ethanol in the presence of sodium ethoxide (Scheme 38). ${ }^{62}$ The structure of the isolated products was evidenced by alternate synthesis of $93(\mathrm{R}=\mathrm{PhN}=\mathrm{N}-, \mathrm{X}=\mathrm{H})$. Thus reaction of 1,5-diphenyl3-mercaptoformazan 95 with either 2,3-dichloroquinoxaline 94a or 2-amino-3-chloroquinoxaline 94b in ethanol in the presence of triethylamine afforded in each case a product that proved identical in all respects with the one obtained above from reaction of 92 with 1,5-diphenyl-3chloroformazan (Scheme 38). ${ }^{62}$

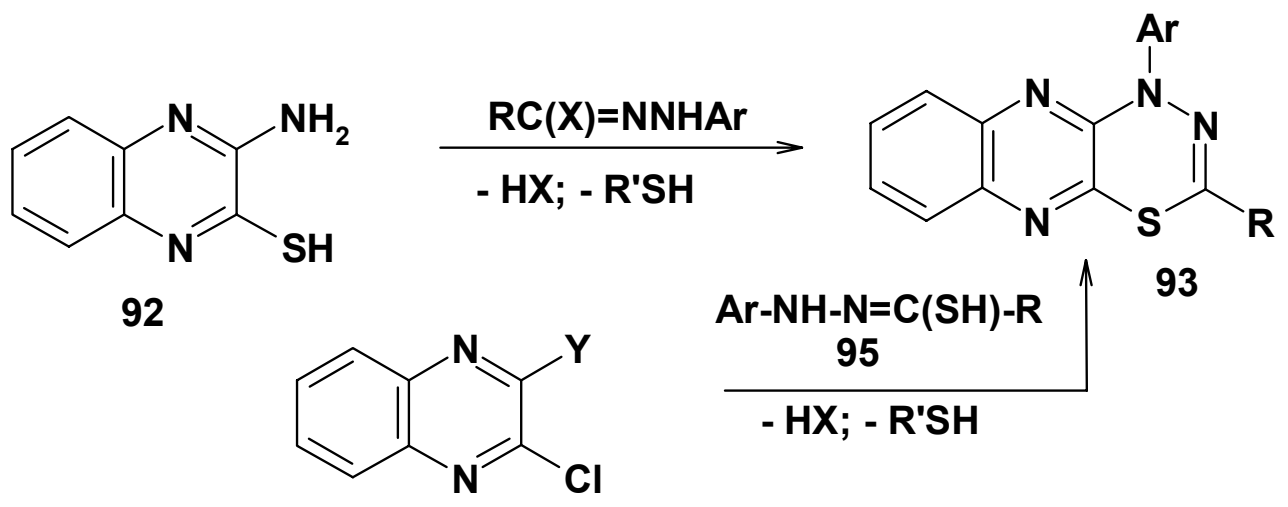

94

$$
\begin{array}{ll}
\mathrm{Y}=\mathrm{a}, \mathrm{Cl} ; \mathrm{b}, \mathrm{NH}_{2} \quad \mathrm{R}=\mathrm{Ph} ; \text { EtOCO; ArN=N-; Ac } \\
\text { PhNHCO; 2-Thenoyl; 2-Naphthoyl }
\end{array}
$$

\section{Scheme 38}

\subsection{Heteroannulation of triheterocycles}

2.3.1. Benzothieno[2,3- $d$ ]pyrimidinethiones. Reactions of 3-amino-2,3,5,6,7,8-hexahydro-2thioxo[1]benzo-thieno [2,3-d]pyrimidin-4(3H)-one 96a and its 2-methylthio derivative 96b with hydrazonoyl halides in ethanol in the presence of triethylamine afforded the fused tetrazine derivatives 97 as end products (Scheme 39). ${ }^{58,63}$ 
<smiles>[R7]c1nc2sc3c(c2c(=O)n1N)CCCC3</smiles>

96

\section{$\mathbf{R}^{\prime}: \mathbf{a}, \mathrm{H} ; \mathrm{b}, \mathrm{Me}$ \\ $\mathrm{R}=\mathrm{Ph} ; \mathrm{EtOCO}$; $\mathrm{PhCH}=\mathrm{CH}-$;}

PhNHCO; 2-Thenoyl; 2-Naphthoyl;

(2-phenyl-4-methylthiazol-5-yl)CO

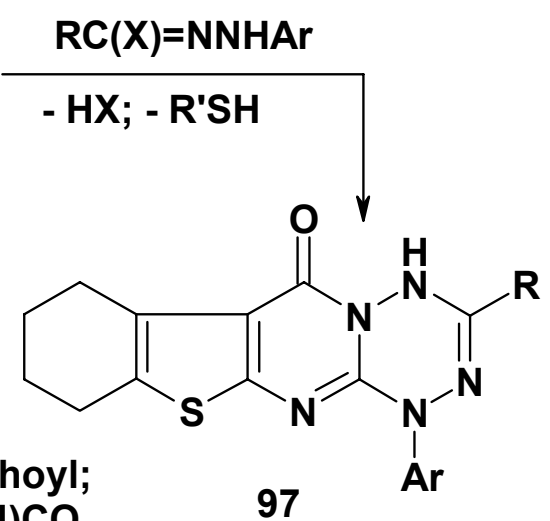

97

Scheme 39

2.3.2. Pyrido $\left[3^{\prime}, 2^{\prime}: 4,5\right]$ thieno[2,3-b]pyrimidinethiones. Reaction of hydrazonoyl halides with 98 in dioxane in refluxing dioxane in the presence of triethylamine gave pyrido[3', $2^{\prime}$ : 4,5] thieno[3,2- $d][1,2,4]$ triazolo[5,4-a]pyrimidin-5-one $99 .{ }^{64}$ The mechanism of the studied reactions and the structure of the products were evidenced by spectral data and alternate synthesis (Scheme 40). ${ }^{64}$<smiles>Cc1cc(C)c2c(n1)sc1c(=O)[nH]c(SCCCCCCCS)nc12</smiles>

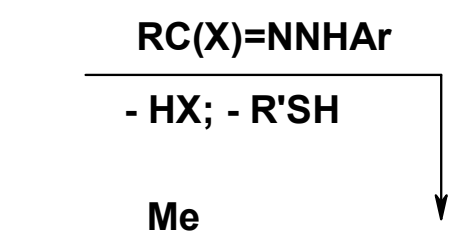

R': a, H; b, Me

R = Ph; EtOCO; 2-furoyl; Ac; PhCO

PhNHCO; 2-Thenoyl<smiles>[R]c1nn(CCCCCC)c2nc3c(sc4nc(C)cc(C)c43)c(=O)n12</smiles>

99

\section{Scheme 40}

Similar reaction of hydrazonoyl halides with each of 3-amino-2,3-dihydro-7,9-dimethyl-2thioxo-pyrido[3',2':4,5]-thieno[2,3-d]pyrimidin-4(3H)-one 100a and its 2-methyl derivative 100b in ethanol in the presence of triethylamine afforded the fused tetrazine derivatives $\mathbf{1 0 1}$ as end products (Scheme 41). ${ }^{65}$ 
<smiles>[R1]c1nc2c(sc3nc(C)cc(C)c32)c(=O)n1N</smiles>

R': a, H; b, Me

R = Ph; EtOCO; 2-furoyl; Ac; PhCO

PhNHCO; 2-Thenoyl; 2-Naphthoyl<smiles>[R]C1=NN([Al])c2nc3c(sc4nc(C)cc(C)c43)c(=O)n2N1</smiles>

101

\section{Scheme 41}

However, reaction of the thione 100a with hydrazonoyl halides in ethanol in the presence of sodium ethoxide at room temperature led to the formation of the thiohydrazonate ester. Treatment of the latter with glacial acetic acid produced the respective 2arylhydrazonopyrido[3",2": $\left.4^{\prime}, 5^{\prime}\right]$ thieno[3',2':4,5]pyrimido[2,1-b][1,2,4]thiadiazinones $\mathbf{1 0 2}$ and 103. The structure of $\mathbf{1 0 2}$ was evidenced by alternate synthesis via coupling of $\mathbf{1 0 4}$ with the appropriate diazotized anilines (Scheme 42). ${ }^{65}$

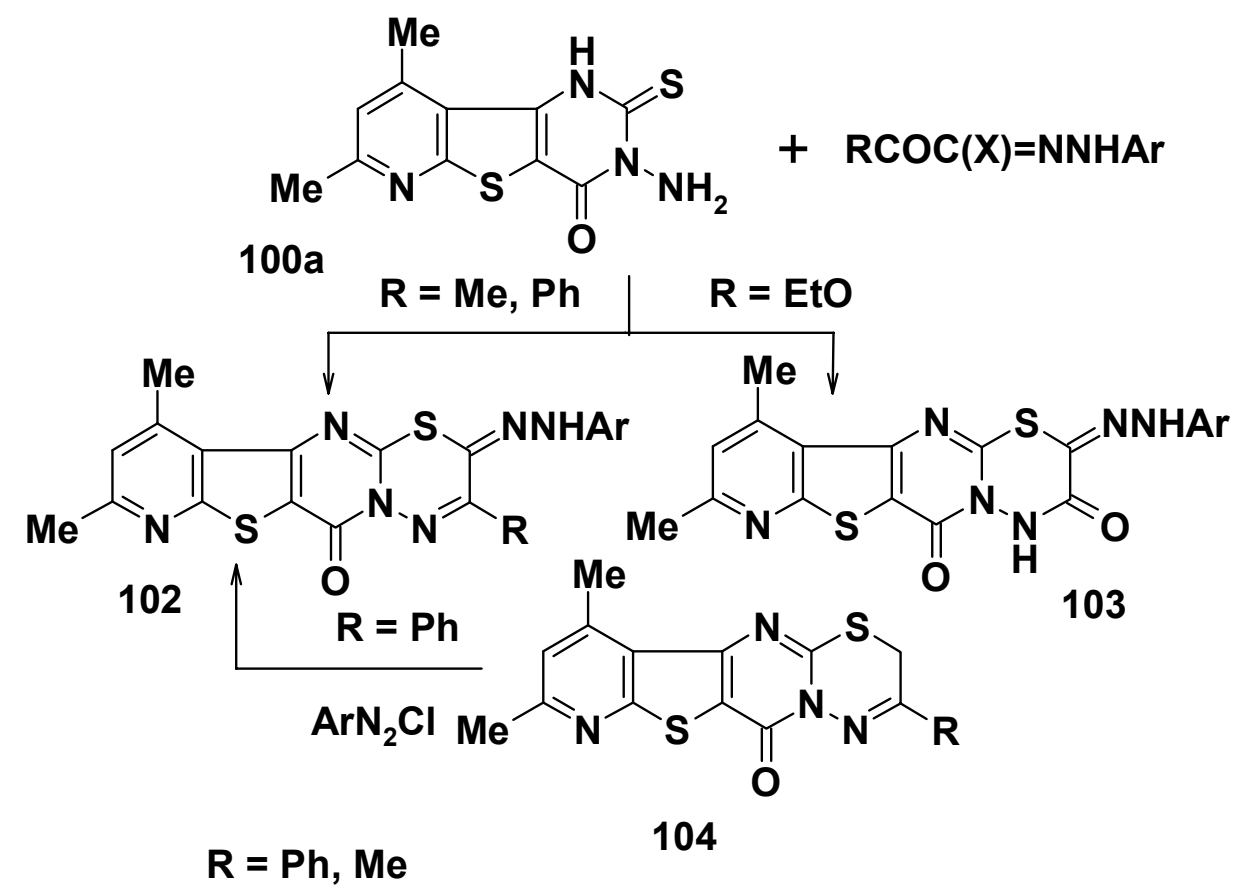

Scheme 42 
2.3.3. Cyclohepta [4,5]-thieno[2,3-d]pyrimidinthiones. Recently various functionalized derivatives of $5 H$-cyclohepta[4,5]-thino[2,3- $d][1,2,4]$ triazolo[4,3- $a]$ pyrimidin-5-one 106 were synthesized via reaction of hydrazonoyl halides with either 2,3,5,6,7,8,9-heptahydro-2-thioxo$4 H$-cyclohepta[4,5]thino[2,3-d] pyrimidin-4-one 105a or its methylthio derivative 105b. The mechanism and the regioselectivity of these reactions were inviestigated and discussed (Scheme 43). ${ }^{66}$<smiles>[R7]c1nc2sc3c(c2c(=O)[nH]1)CCCCC3</smiles>

105

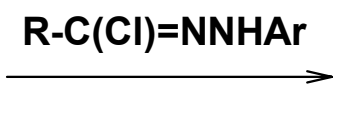

R': a, H; b,Me

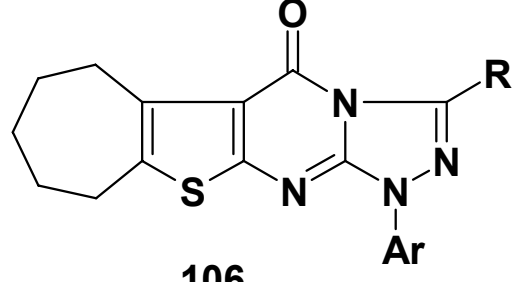

106

R : Ph; EtOCO; Ac; PhNHCO, PhCO

\section{Scheme 43}

Treatment of the thione $107 \mathbf{a}$ or its methylthio derivative $\mathbf{1 0 7} \mathbf{b}$ each with hydrazonoyl halides in ethanol in the presence of sodium ethoxide at room temperature gave the respective 1,3-disubstituted $1,7,8,9,10,11$-hexahydro-4H,6H-cyclohepta[4',5']thieno[2',3':4,5]pyrimido[1,2b][1,2,4,5]tetrazin-6-one 108 (Scheme 44). ${ }^{67}$

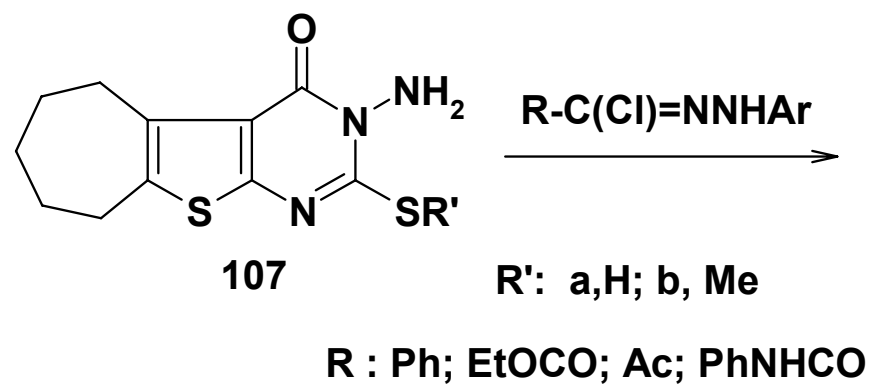

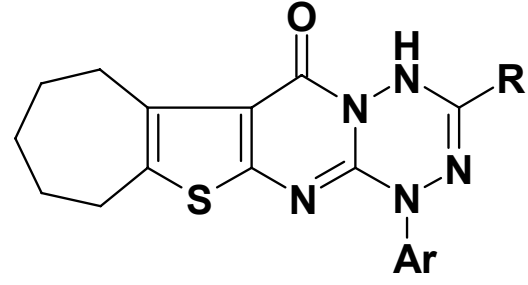

108

\section{Scheme 44}

2.3.4. Pyrido[2,3-d : 6,5- $\left.\boldsymbol{d}^{\prime}\right]$ dipyrimidinethione. Reaction of 2,8-dihydropyrido[2,3-d:6,5$d$ ']dipyrimidine-4,6(1H,7H)- dione $\mathbf{1 0 9}$ with hydrazonoyl chlorides in ethanol in the presence of triethylamine at room temperature was found to give products identified as the bisthiohydrazonate esters 110 (Scheme 45). Treatment of 110 with sodium ethoxide in refluxing ethanol gave the products $\mathbf{1 1 1}$ via in situ Smiles rearrangement ${ }^{34}$ of $\mathbf{1 1 0}$ followed by cyclization with concurrent elimination of hydrogen sulfide (Scheme 45). ${ }^{36}$ That the isolated products from the latter treatment have the structure 111 and not its isomer 112, was confirmed by their alternate synthesis. Thus, treatment of the dithione 109 with two molar equivalents of ethyl 2- 
chloro-3-oxobutanoate in ethanol in the presence of potassium hydroxide at room temperature yielded the substitution product 113 (Scheme 46). ${ }^{36}$ Treatment of 113 with $p$ chlorobenzenediazonium chloride in ethanol in the presence of sodium acetate at low temperature $\left(0-5^{\circ} \mathrm{C}\right)$ yielded product identical in all respects with the product $110 \mathrm{Cc}$ isolated from reaction of $\mathbf{1 0 9}$ with $N$-(p-chlorophenyl)-C-ethoxycarbonylnitrilimine (Scheme 45). Treatment of the 110Cc with sodium ethoxide in ethanol in attempt to get the respective bisthiohydrazide, was found to give 111Cc directly as end product (Scheme 46). ${ }^{36}$

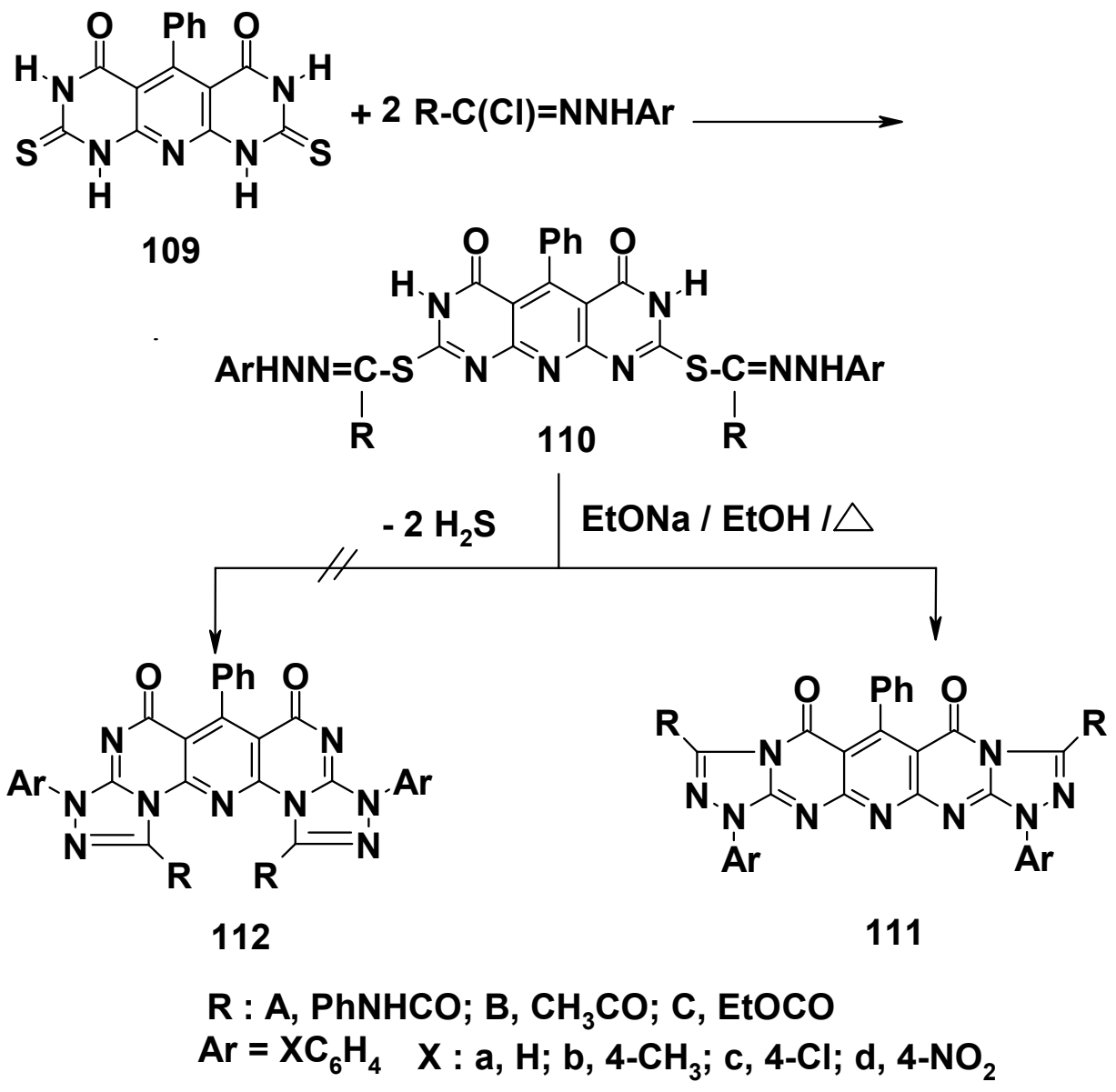

Scheme 45 


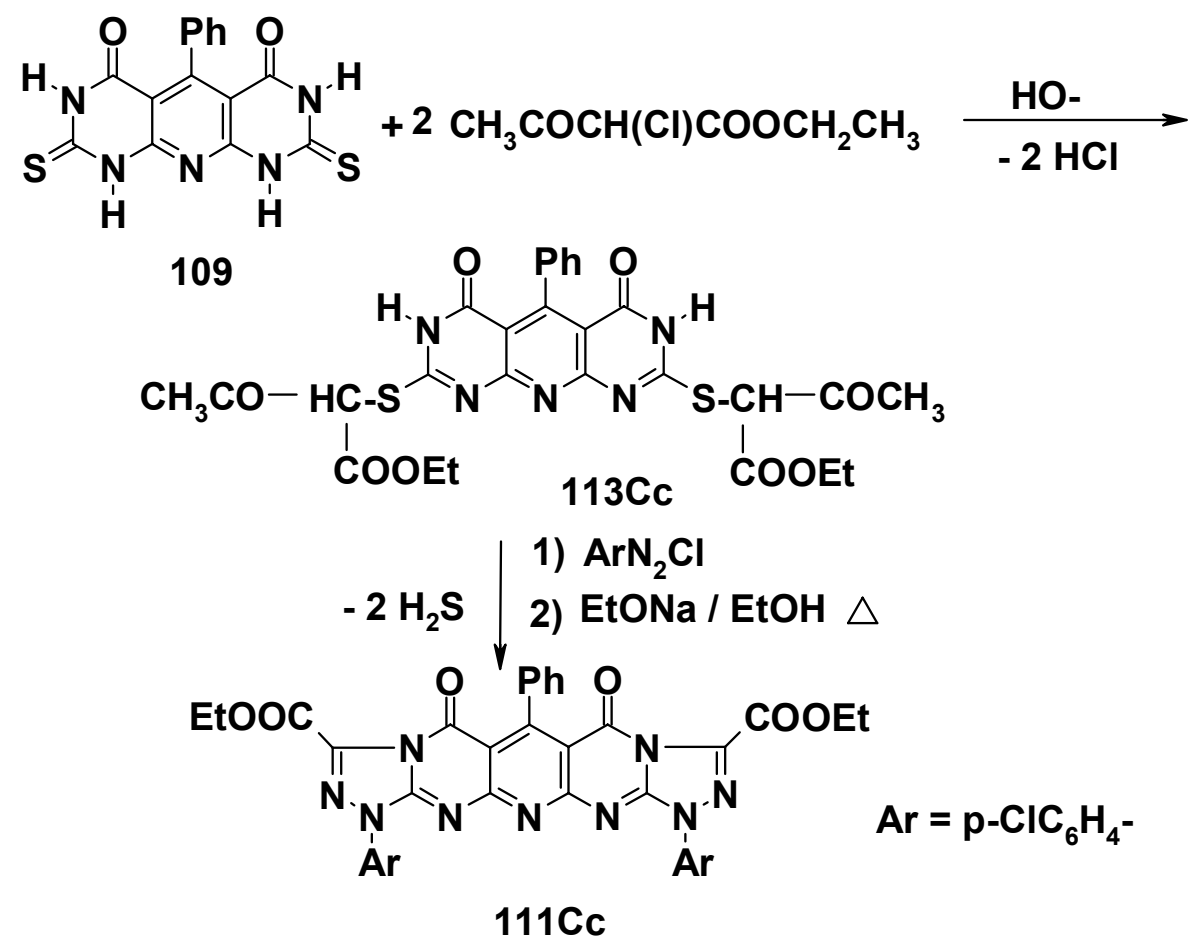

Scheme 46

\subsection{Heteroannulation of tetraheterocycles}

2.4.1. Naphtho[2,1-e]pyrido[2,3-c]pyrimidinethiones. Naphtho[2,1-e]pyrido[2,3c]pyrimidinethione derivatives 114 reacted with hydrazonoyl halides and yielded the respective fused naphthotriazolopyridopyrimidines 115 (Scheme 47). ${ }^{68}$<smiles>O=c1c2c(Br)c3c(nc2[nH]c(=S)n1F)-c1ccccc1CC3</smiles><smiles>[R]C(=O)NNC(C)C1CCc2c(nc3nc4n([Al])nc([R])n4c(=O)c3c2Br)-c2ccccc21</smiles>

$$
A r^{\prime}=4-\mathrm{CIC}_{6} \mathrm{H}_{4} \quad \mathrm{R}=\mathrm{Ph} ; \mathrm{Ac} ; \text { EtOCO }
$$

Scheme 47 


\section{Synthesis of spiroheterocycles}

The reaction of heterocyclic thiones $\mathbf{1 1 6}$ with nitrilimines, generated in situ by base-catalyzed dehydrohalogenation of hydrazonoyl halides, has been described for synthesis of various derivatives of spiro[heterocycle-n,2'-3H-1,3,4-thiadiazole] 117 (Fig. 1).

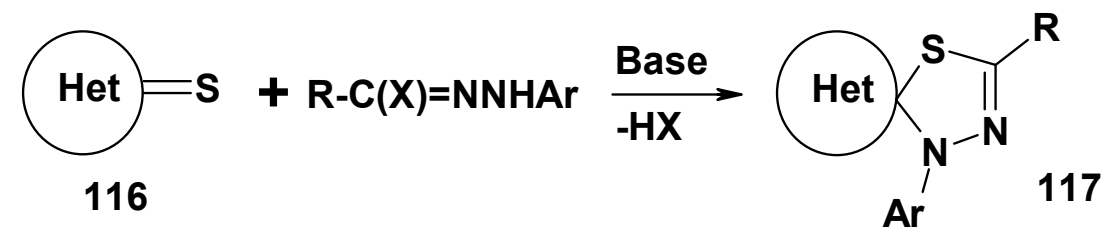

\section{Figure 1}

Thus, reaction of 2-oxoalkanehydrazonoyl halides reacted with 4-oxo-1,3diphenylimidazole-2-thione $\mathbf{1 1 8}$ in chloroform in the presence of triethylamine gave the corresponding spiro[imidazole-2,2'-3H-1,3,4-thiadiazole] derivatives $\mathbf{1 1 9}$ in $75-77 \%$ yield (Scheme 48). ${ }^{69}$ This finding indicates that the dipolarophilicity of the $\mathrm{C}=\mathrm{S}$ group is more than that of the $\mathrm{C}=\mathrm{O}$ group.<smiles>O=C1CN(c2ccccc2)C(=S)[NH+]1c1ccccc1</smiles>

118<smiles>[R]C(=O)C([X])=NN([AlH2])[AlH2]</smiles>

$\mathrm{R}=\mathrm{Me}, \mathrm{Ph}, \mathrm{EtO}$

\section{Scheme 48}

Similar reaction of 5-phenylmethylene-1,3-diphenyl-5-oxo-2-thioxo-tetrahydroimidazole 120 with hydrazonoyl halides in chloroform in the presence of triethylamine afforded, however, spiro[5H-pyrazolo-4,4'-imidazole] 121 in $78-80 \%$ yield via cycloaddition of the in situ generated nitrilimines on the exocyclic $\mathrm{C}=\mathrm{C}$ double bond. This result indicates that the $\mathrm{C}=\mathrm{S}$, while being more reactive dipolarophile than the $\mathrm{C}=\mathrm{O}$ double bond, is less reactive than the enone moiety of 120 (Scheme 49). ${ }^{69}$ 
<smiles>[R]C(=O)C([R])=NN([AlH2])N=C([X])C</smiles>

120<smiles>[R]OC1=NN(c2ccccc2)C(c2ccccc2)C12C(=O)N(c1ccccc1)C(=S)N2c1ccccc1</smiles>

121

\section{Scheme 49}

On the other hand, the spiro[3H-thiazole-2,2'-3H-thiadiazole] derivatives 123 were formed by reaction of 3-phenyl-4-phenylmethylene-2-thioxothiazolin-5-one $\mathbf{1 2 2}$ with nitrilimines, generated in situ by the action of triethylamine on hydrazonoyl halides in refluxing chloroform (Scheme 50). ${ }^{70}$ In this case, the $\mathrm{C}=\mathrm{S}$ double bond seems to be more dipolarophilic than both the enamine or enone $\mathrm{C}=\mathrm{C}$ double bond.<smiles>[R]C1=NN([AlH2])C2(SC(=O)C(=Cc3ccccc3)N(c3ccccc3)C2[R])S1</smiles>

122

$$
\begin{gathered}
\text { R = EtOCO, Ph, PhCO, 2-thenoyl, PhNHCO, } \\
\text { Ac, } \mathrm{PhCH}=\mathrm{CH}, 2 \text {-naphthoyl, 2-furyl }
\end{gathered}
$$

\section{Scheme 50}

Various substituted derivatives of spiro[thiazole-2,2'-3H-1,3,4-thiadiazole] 125 were prepared in good yield by reaction of hydrazonoyl halides with 5-arylmethylene-3-phenyl-2thioxothiazolidin-4-one $\mathbf{1 2 4}$ in chloroform in the presence of triethylamine (Scheme 51). ${ }^{71}$<smiles>O=C1/C(=C/c2ccccc2)SC(=S)N1c1ccccc1</smiles>

124<smiles></smiles>

Ar<smiles>[R]C1=NN([AlH2])C2(SC(=Cc3ccccc3)C(=O)N2c2ccccc2)S1</smiles>

125

\section{$\mathrm{R}=\mathrm{Ph}, \mathrm{PhCH}=\mathrm{CH}, \mathrm{PhCO}$, 2-thenoyl, 2-naphthoyl, Ac, EtOCO, PhNHCO}

Scheme 51 
Diphenylnitrilimine, derived from thermolysis of 3,5-diphenyltetrazole in mesitylene, cycloadded to 5-thioxothiazoline derivative 126 to give $83 \%$ of spiro[5H-thiazole-5,2'-3H-1,3,4thiadiazole] 127 (Scheme 52). ${ }^{72}$

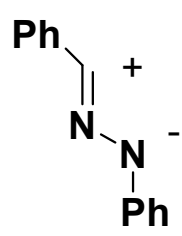

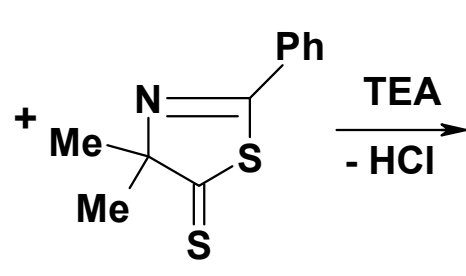

126<smiles>CC1(C)N=C(c2ccccc2)SC12SC(c1ccccc1)=NN2c1ccccc1</smiles>

127

\section{Scheme 52}

Also, diphenylnitrilimine, derived from $N$-phenylbenzencarbohydrazonoyl chloride, reacted with 3,5-diphenyl-1,3,4-thiadiazine-2-thione $\mathbf{1 2 8}$ and afforded the respective derivative of spiro[3H-1,3,4-thiadiazole-2,2'-3H-1,3,4-thiadiazole] 129 (Scheme 53). ${ }^{73}$<smiles>S=c1sc(-c2ccccc2)nn1-c1ccccc1</smiles>

128<smiles>Cl/C(=N/Nc1ccccc1)c1ccccc1</smiles>

Ph<smiles>CCCl</smiles>

$\mathbf{P}$<smiles>Pc1ccccc1</smiles>

129

\section{Scheme 53}

Heating a mixture of $N$-phenyl benzenecarbohydrazonoyl chloride and 1,2 -dithioline-3thiones $\mathbf{1 3 0}$ in chloroform in the presence of triethylamine yielded 1,2,4-thiadiazoline derivatives 132. The latter products were said to result via ring cleavage of the initially formed spiro[1,2dithioline-3,2'-3H-1,3,4-thiadiazole] cycloadducts 131 (Scheme 54). ${ }^{74}$ 
<smiles>C/C(=N/Nc1ccccc1)c1ccccc1</smiles><smiles>[3H][I-]I</smiles>

130

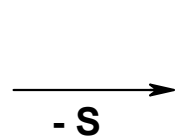<smiles>[R]C(C([Al])=S)=C1SC(c2ccccc2)=NN1c1ccccc1</smiles><smiles>[R]C1=C([Al])SSC12N=NC(c1ccccc1)=N2</smiles>

131

$\mathbf{R}=\mathbf{H}, \mathbf{M e}$

$\mathrm{Ar}=\mathrm{Ph}, 4-\mathrm{MeOPh}, 4-\mathrm{MePh}$

\section{Scheme 54}

Reactions of the pyrimidine-2(1H)-thione 133 and its analog 4(1H)-thione 136 each with one molar equivalent of the appropriate hydrazonoyl halide in benzene in the presence of triethylamine gave under normal conditions the respective spiro cycloadducts 134 and 137 , respectively. Using two mole equivalents of hydrazonoyl halide in the reaction with pyrimidine2(1H)-thiones 133 led to the 2:1 cycloadducts 135 (Scheme 55). ${ }^{75}$ The structure of the latter biscycloadduct 135 needs further investigation as it results from $4 \pi+4 \pi$ cycloaddition which is thermally forbidden.

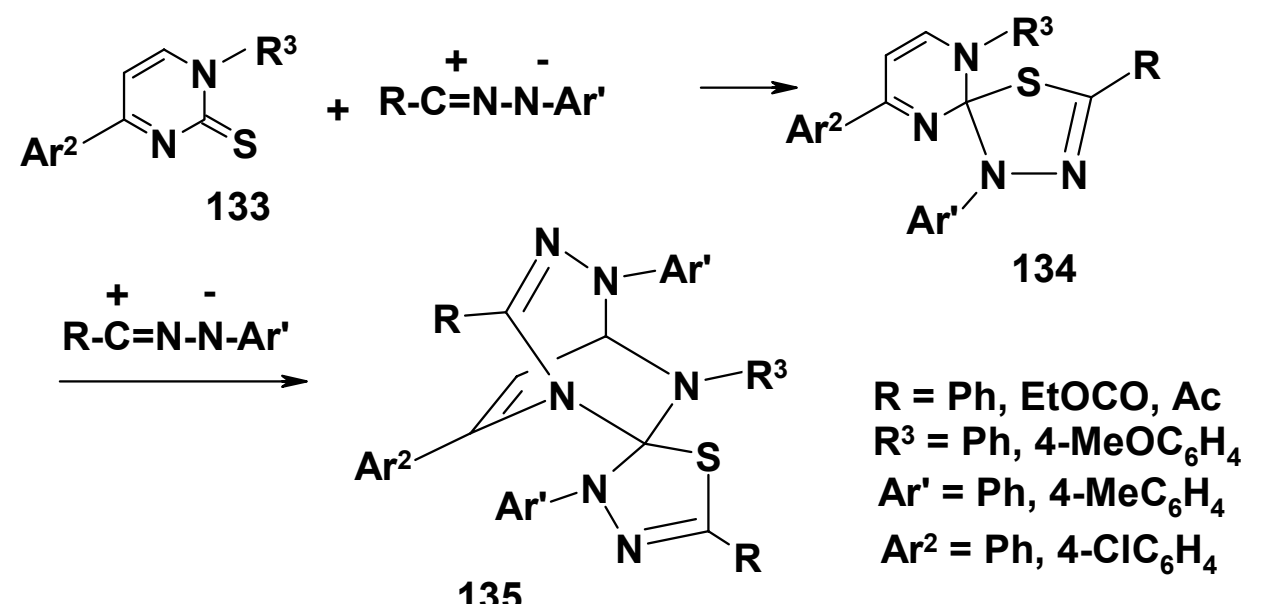




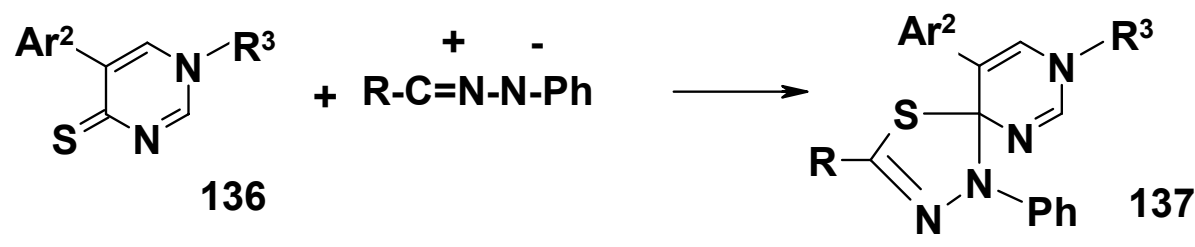

$$
\begin{aligned}
\mathrm{R}= & \mathrm{Ph}, \mathrm{Ac}, \text { EtOCO } \\
\mathrm{R}^{3}= & 4-\mathrm{Me}, \mathrm{CH}_{2} \mathrm{COOEt}, \mathrm{Me}, \\
& 4-\mathrm{CIC}_{6} \mathrm{H}_{4}, \mathrm{CH}_{2} \mathrm{COOMe} \\
\mathrm{Ar}^{2}= & \mathrm{Ph}, 4-\mathrm{ClC}_{6} \mathrm{H}_{4}
\end{aligned}
$$

\section{Scheme 55}

Spiro[3H-1,3,4-thiadiazole-2,3'-2H-pyridazine] derivatives 139 were prepared by reaction of 6-thioxo-1,6-dihydropyridazines 138 with N-phenyl 2-oxopropanehydrazonoyl chloride (Scheme $56) .{ }^{76-78}$<smiles>[R]c1ccc(=S)n([R][K])n1</smiles>

138

$$
\begin{aligned}
\mathrm{R} & =\mathrm{Ac}, \mathrm{EtOCO} \\
\mathrm{R}^{\prime} & =4-\mathrm{CIC}_{6} \mathrm{H}_{4}, \mathrm{CH}_{3}, \mathrm{Ph} \\
\mathrm{R}^{\prime \prime} & =\mathrm{H}, \mathrm{Ph}
\end{aligned}
$$

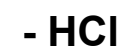

\section{Scheme 56}

Also, spiro[3H-1,3,4-thiadiazole-2,6'-1,4,5,6-tetrahydro-1,2,4-triazine] 141 was said to be formed when 3-phenyl-4,5-dihydro-1,2,4-triazin-6(1H)-thione $\mathbf{1 4 0}$ with N-methyl benzenecarbohydrazonoyl bromide in chloroform in the presence of triethylamine. However, this spirocycloadduct $\mathbf{1 4 1}$ was said to be unstable so that full characterization could not be achieved (Scheme 57). ${ }^{77}$

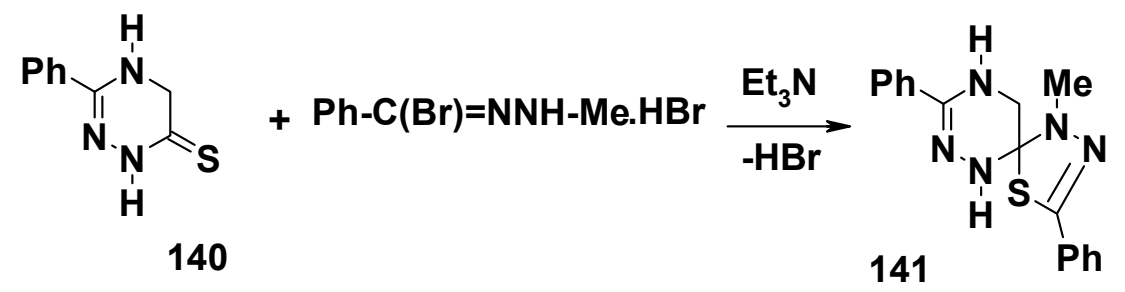

\section{Scheme 57}


2,3,3-Triphenyl-1-thioxophthalimidine 142 reacted with hydrazonoyl halides in boiling benzene in the presence of triethylamine afforded 2,3,3,3',5'-pentasubstituted spiro[benzopyrolidine-1,2'-(2',3'-dihydro)-[1',3'4']-thiadiazoles] 143 (Scheme 58). ${ }^{79}$

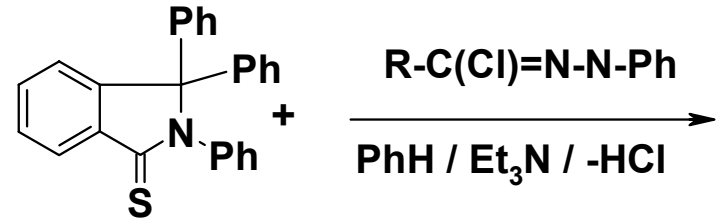

142
143<smiles>[R]C1=NN(c2ccccc2)C2(S1)c1ccccc1C(c1ccccc1)(c1ccccc1)N2P</smiles>

$$
\mathrm{R}=\mathrm{Ph}, 4-\mathrm{NO}_{2} \mathrm{C}_{6} \mathrm{H}_{4}, \mathrm{Ac}, \mathrm{PhCO}, \text { EtOCO }
$$

\section{Scheme 58}

Spiro[3H-1,3,4-thiadiazole-2,2'-benzothiophenes] 145 were also prepared from 1,2dithiophthalides 144 and nitrilimines, derived from the respective hydrazonoyl halides (Scheme 59). ${ }^{80}$

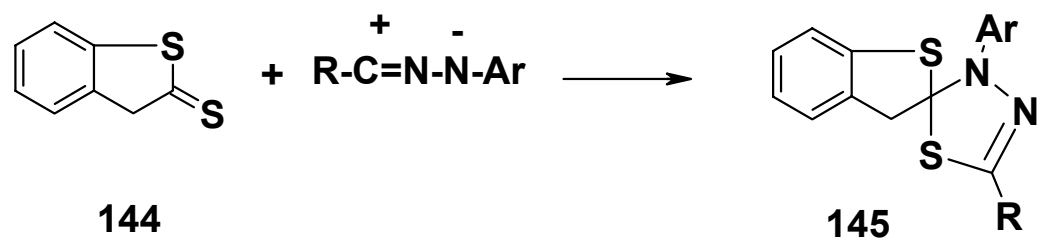

\section{Scheme 59}

Similarly, reaction of hydrazonoyl halides with 1-thioxo-3,3-diphenyl-isobenzothiophene 146 yielded $80 \%$ of the respective spiro[3H-1,2,4-triazole-2,1'-1H,3H-isobenzothiophenes] 147 (Scheme 60). ${ }^{81}$
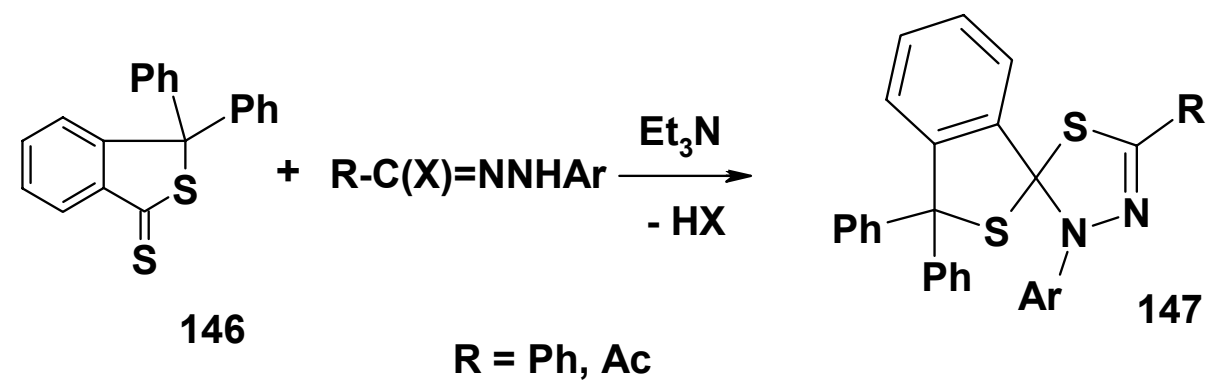

Scheme 60 
Contradicting results regarding the site selectivity in the reaction of 4H-1-benzopyran-4thione 148 with hydrazonoyl halides were reported. Thus, in one report, ${ }^{82}$ such a reaction was reported to proceed smoothly and gave the cycloadduct 149 (Scheme 61). In another report, ${ }^{83}$ the product isolated from the reaction of 148 with $N$-p-bromophenyl 2-oxopropanehydrazonoyl chloride in the presence of triethylamine was shown on the basis of X-ray analysis to be spiro[3H-1,3,4-thiadiazole-2,4'-4'H-1-benzopyran] 150 (Scheme 61).

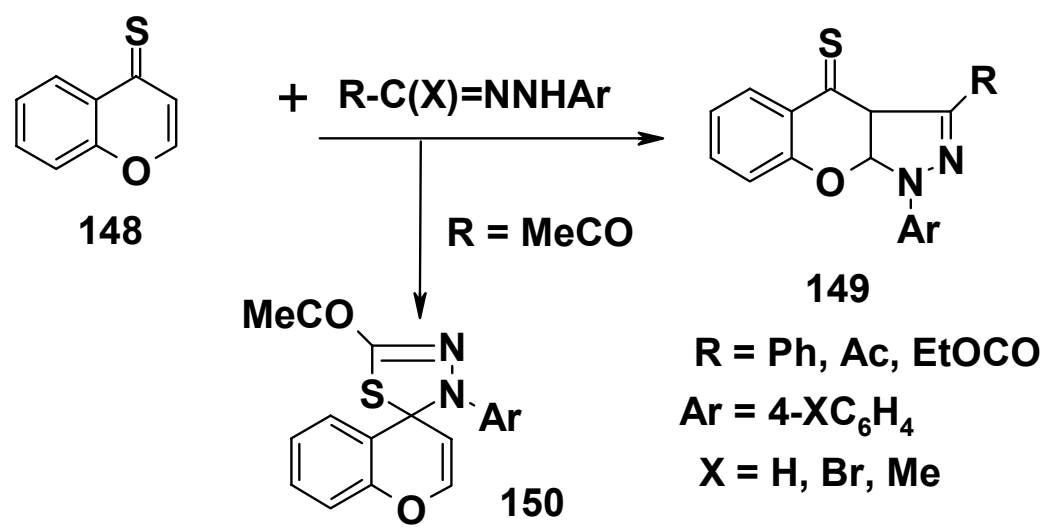

\section{Scheme 61}

Furthermore, spiro[3H-1,3,4-thiadiazole-2,4'-4H-benzopyran] derivatives 152 were obtained by the reaction of 3-cyano-4H-1-benzopyran-4-thione 151 with hydrazonoyl halides in chloroform in the presence of triethylamine (Scheme 62). ${ }^{84}$<smiles>N#Cc1coc2ccccc2c1=S</smiles>

151

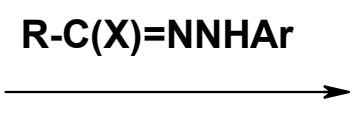

$R=A c, E t O C O$ $\mathrm{Ar}=4-\mathrm{MeC}_{6} \mathrm{H}_{4}, 4-\mathrm{BrC}_{6} \mathrm{H}_{4}$<smiles>[R]C1=NN([Al])C2(S1)C(C#N)=COc1ccccc12</smiles>

152

\section{Scheme 62}

Heating a mixture of thioxophthalazines 153 and hydrazonoyl halides in chloroform in the presence of triethylamine afforded the respective spiro[3H-1,3,4-thiadiaole-2,4'-3H-quinazoline] derivatives 154 in $75-80 \%$ yield (Scheme 63 ). ${ }^{85}$ 


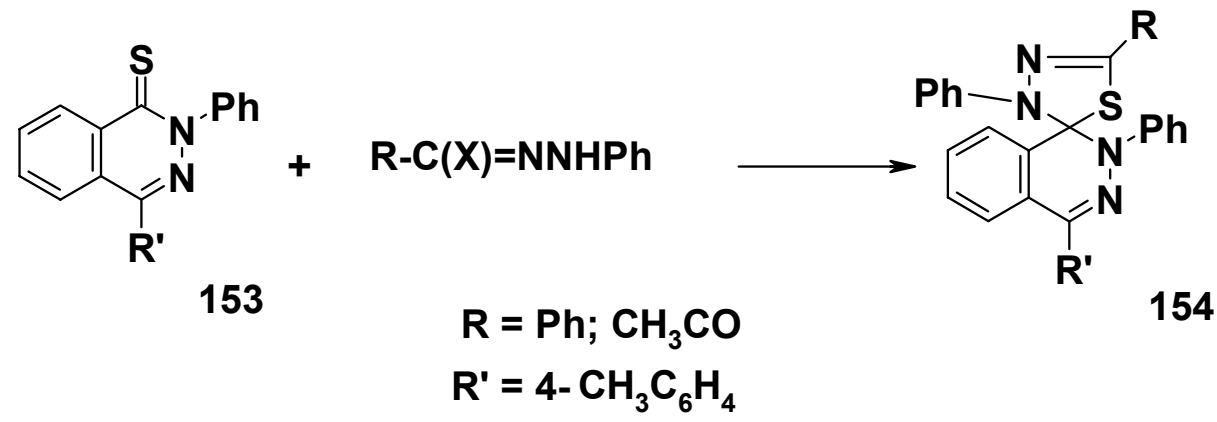

\section{Scheme 63}

Reaction of pyrazolo[1,5,4-ef][1,5]benzodiazepine-6-thione $\mathbf{1 5 5}$ with N-aryl-Cethoxycarbonylnitrilimines, generated in situ by the action of triethylamine on the respective ethyl $N$-arylhydrazonochloroacetate, yielded the respective spiro[4H-1,4-diazepin-6-ene[1,2,3hi] imidazole-2,2'-2H-1,3,4-thiadiazole] 156 (Scheme 64). ${ }^{86}$

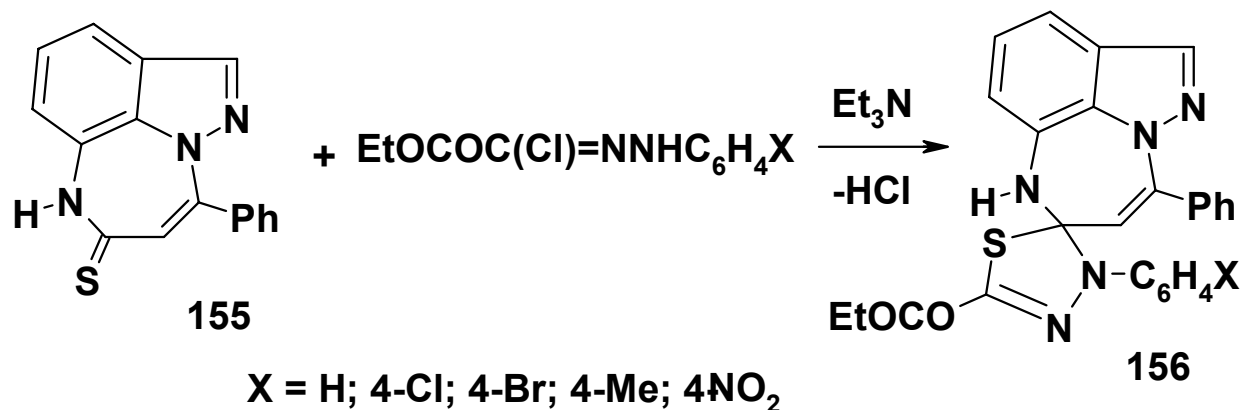

Scheme 64

\section{Heterocyclic ring transformations}

\subsection{Transformation of azetine-2-thiones into 1,3,4-triazoles}

Reactions of 2-ethylthio-3,3,4,4-tetreamethyl-azetine 158, derived from the respective thione 157, with $N$-phenylbenzenecarbohydrazonoyl chloride in refluxing benzene in the presence of triethylamine was reported to give 5-(2,3-dimethylbuten-1-en-3-yl)-1,3-diphenyl-1,2,4-triazole 159a whose structure was evidenced by ${ }^{1} \mathrm{H}$ NMR and X-ray analyses as well as chemical reactions (Scheme 65). ${ }^{87}$ Similar reaction of $\mathbf{1 6 0}$ with the same hydrazonoyl chloride under the same conditions afforded 162a in 73\% yield. However, reaction of 160 with $N$-(4-nitrophenyl) benzenecarbohydrazonoyl chloride gave a separable mixture of the tricyclic cycloadduct $\mathbf{1 6 1}$ and 162b (Scheme 65). ${ }^{87}$ On the other hand, no reaction was observed between the latter 
hydrazonoyl chloride and each of 8-(ethylthio-6-methyl-7-azabicyclo[4.2.0]oct-3,7-diene 163a and its 1,6-dimethyl analog $163^{87}$

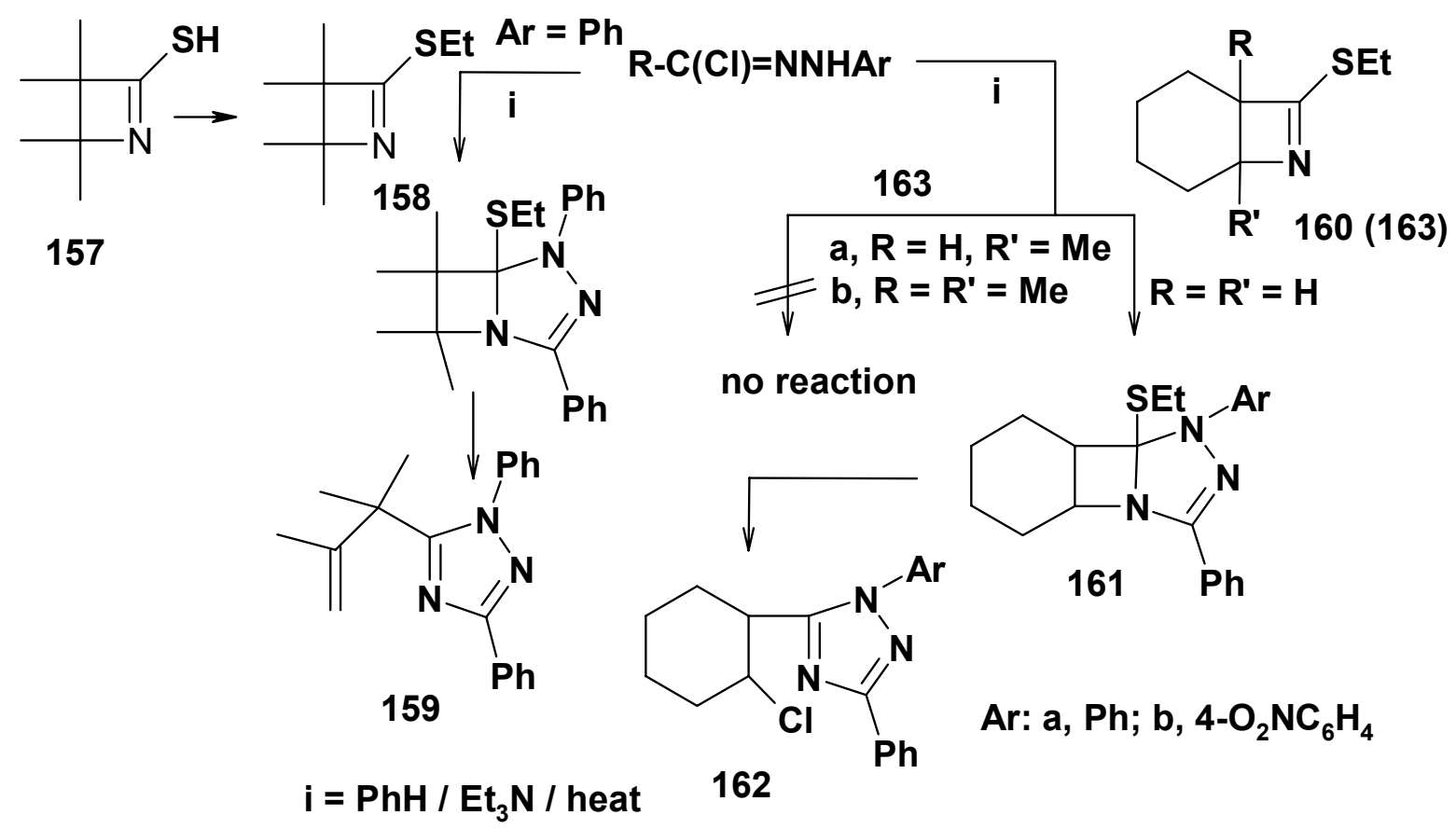

\section{Scheme 65}

\subsection{Transformation of 1,3,4-Oxadiazole-2(3H)-thiones into 1,3,4-thiadiazoles}

In recent reports, Shawali et al. ${ }^{88-90}$ and others ${ }^{91-93}$ indicated that reactions of hydrazonoyl halides with 1,3,4-oxadiazole-2(3H)-thiones 164 afforded 1,3,4-thiadiazol-2(3H)-one derivatives 166. The formation of the latter was assumed to occur via the rearrangement of the initially formed thiohydrazonate esters as intermediate (Scheme 66). Similar reaction of 5-heteroaryl1,3,4-oxadiazole-2(3H)-thione with hydrazonoyl halides in refluxing ethanol in the presence of triethylamine afforded also the corresponding 166 (Scheme 66). ${ }^{25}$ 

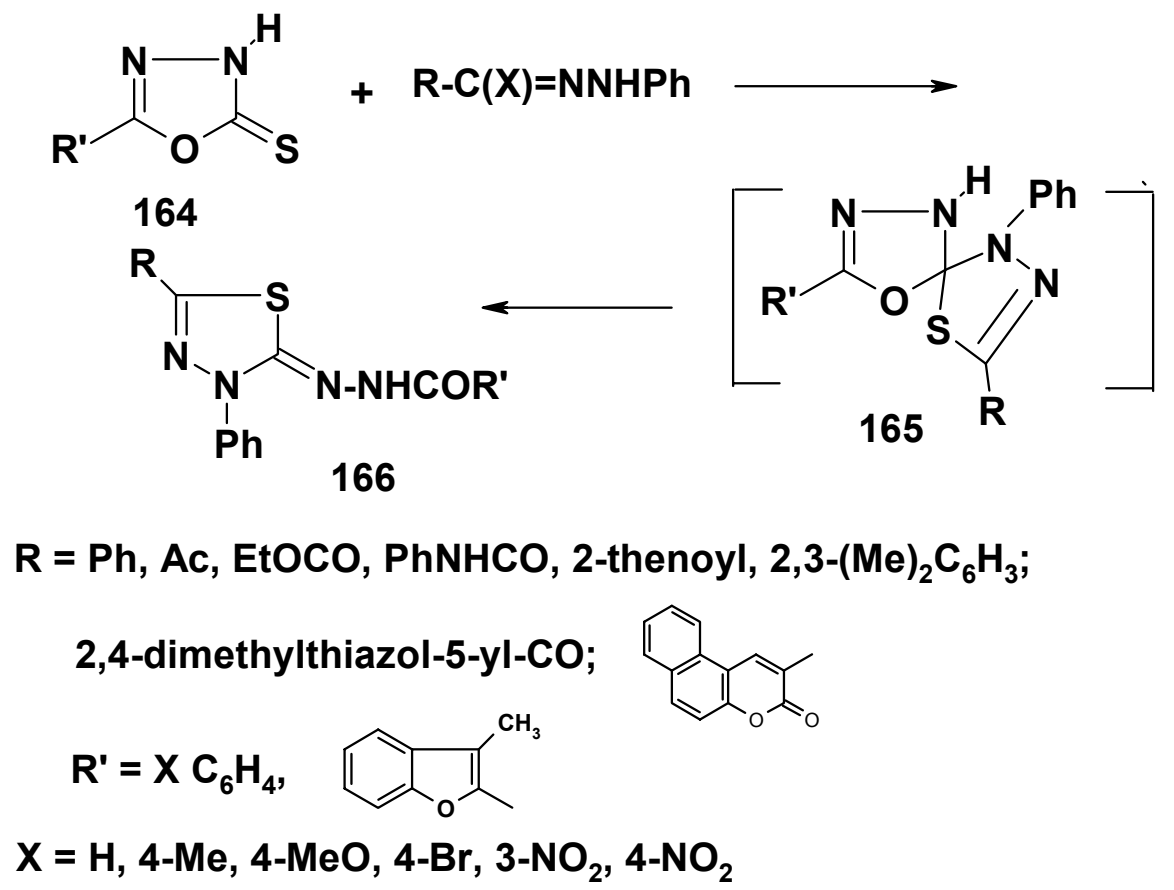

Scheme 66

The involvement of thiohydrazonate $\mathbf{1 6 8}$ as intermediates in the studied reactions was confirmed by alternate synthesis of $\mathbf{1 6 6}$ as depicted in Scheme 67. ${ }^{89,90}$
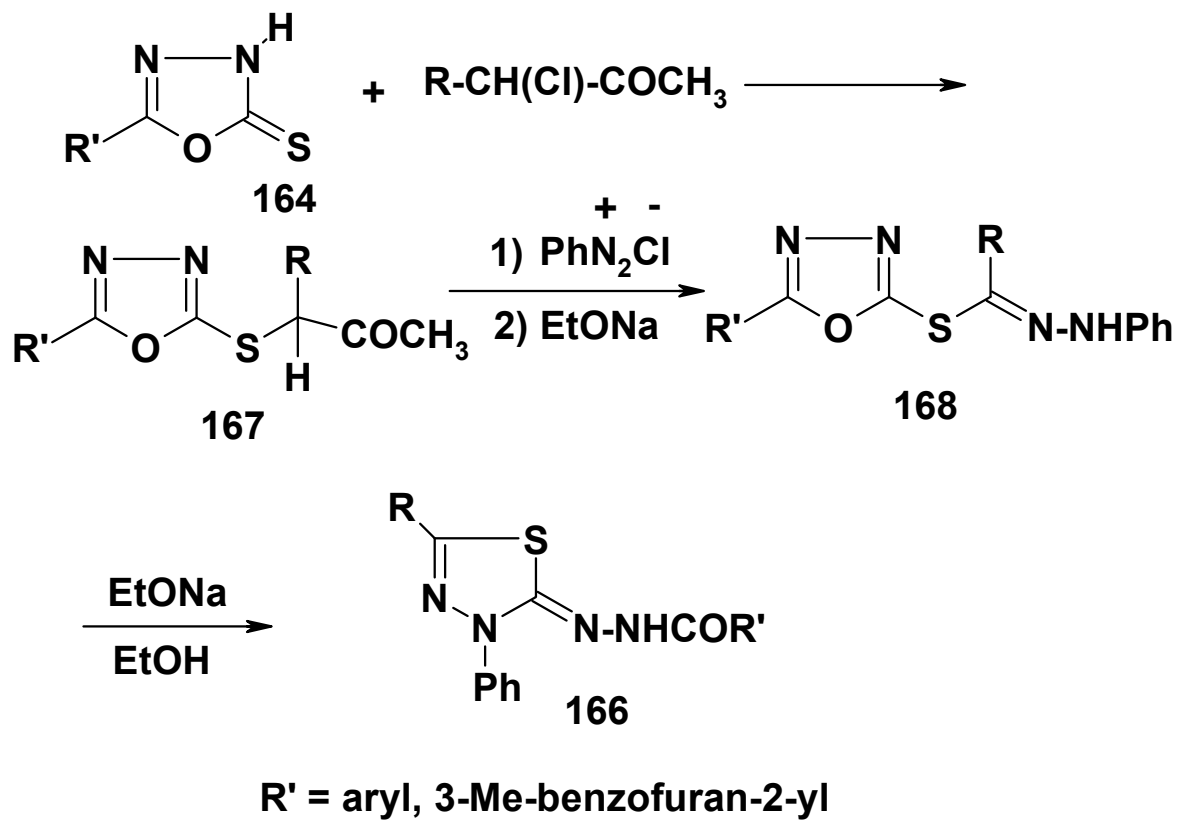

Scheme 67 
Also, reactions of the Mannich bases 169 with hydrazonoyl halides in benzene or ethanol in the presence of triethylamine at room temperature was reported to afford the respective thiadiazoline derivatives 166 (Scheme 68). ${ }^{89}$<smiles>[R]c1nn(CN2CCOCC2)c(=S)o1</smiles>

169

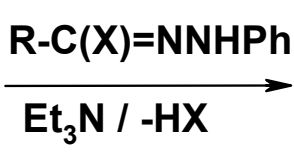

$\mathrm{Et}_{3} \mathrm{~N} /-\mathrm{HX}$<smiles>[R]C(=O)NN=c1sc([R])nn1-c1ccccc1</smiles>

166

\section{Scheme 68}

Reaction of 5-heteroaryl 1,3,4-oxadiazole-2(3H)-thione $\mathbf{1 7 0}$ with hydrazonoyl halides in ethanol in the presence of triethylamine under reflux gave the respective 1,3,4-thiadiazole derivatives 171. ${ }^{94}$ The structure of the latter was confirmed by its alternate synthesis via reaction of hydrazonoyl halides with $N$-acylthiocarbohydrazide 172 (Scheme 69). ${ }^{94}$

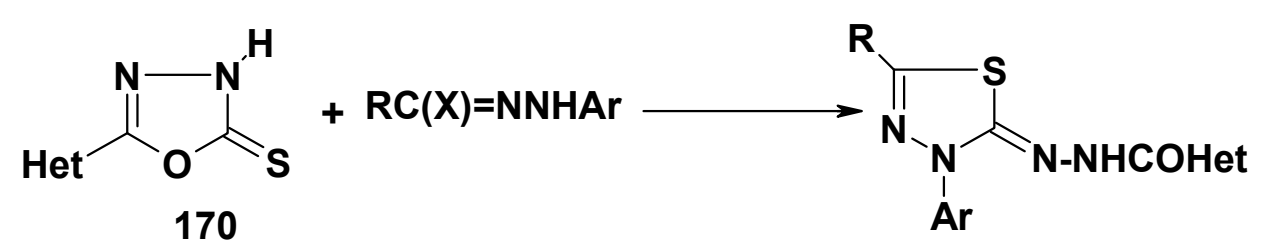

171

\section{Het-CO-NHNHCSNH $2+R C(X)=$ NNHAr}

172

$$
\begin{aligned}
& \text { Het }=\overbrace{\mathrm{H}} \\
& \mathbf{R}=\mathbf{P h}, \mathrm{PhCO}, \mathrm{Ac}, 2-\mathrm{Furoyl}, \text { EtOcO }
\end{aligned}
$$

\section{Scheme 69}

\subsection{Transformation of 1,4,2-dithiazole-5-thiones into 1,3,4-thiadiazoles}

Reaction of benzenecarbohydrazonoyl chloride with 3-substituted 1,4,2-dithiazole-5-thione 173 in benzene in the presence of triethylamine was reported to yield 3,5-diphenylthiadiazole-2thione $\mathbf{1 7 5}^{95}$ The latter products were considered to result via ring cleavage of the initially formed spiro intermediate 174 (Scheme 70). ${ }^{95}$ 

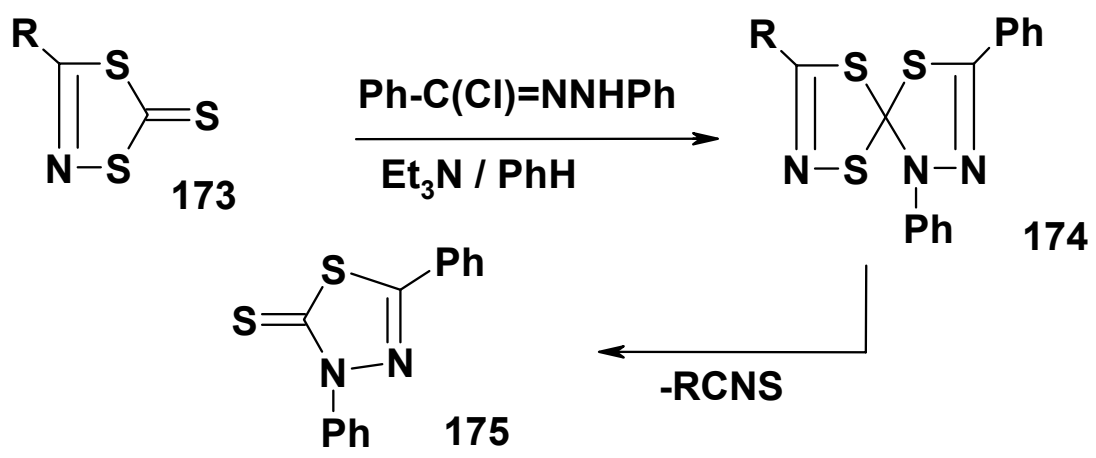

\section{Scheme 70}

\subsection{Transformation of tetrazole-5(1H)-thiones into 1,3,4-thiadiazoles}

Treatment of hydrazonoyl halides with tetrazole-5(1H)-thiones $\mathbf{1 7 6}$ in chloroform in the presence of triethylamine led to the formation of the thiohydrazonate esters $\mathbf{1 7 7}$. When the latter thiohydrazonates were heated in toluene, they were converted into 1,3,4-thiadiazoles 179 (Scheme 71). ${ }^{96}$

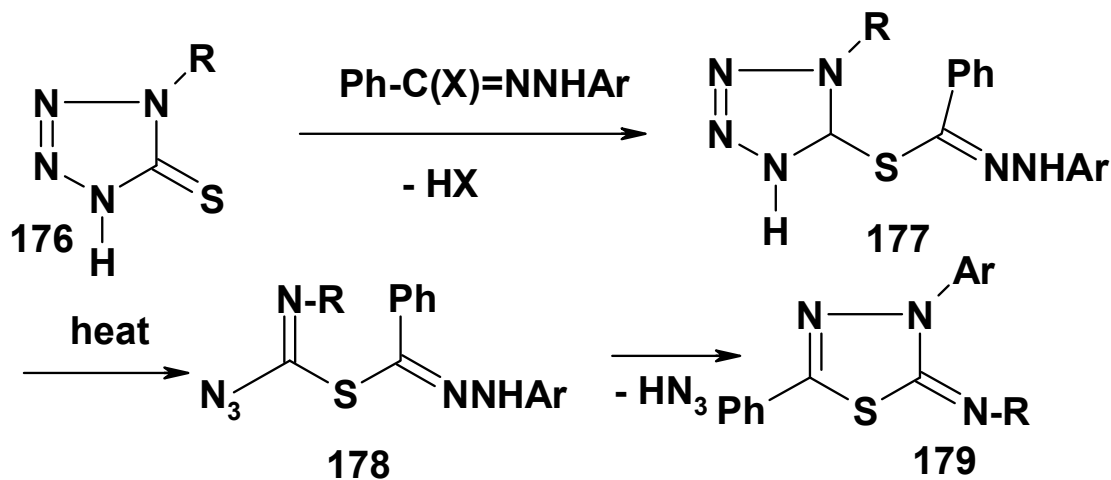

$$
\begin{aligned}
& \mathrm{R}=\mathrm{Ph}, 4-\mathrm{O}_{2} \mathrm{NC}_{6} \mathrm{H}_{4}, 4-\mathrm{MeC}_{6} \mathrm{H}_{4} \\
& \mathrm{Ar}=4-\mathrm{O}_{2} \mathrm{NC}_{6} \mathrm{H}_{4}
\end{aligned}
$$

\section{Scheme 71}

\subsection{Transformation of tetrazoles into 1,2,4,5-tetrazines}

Reaction of 1-phenyltetrazole-5-thione $\mathbf{1 7 6}$ with $\quad N$-(2,4-dibromophenyl) benzenecarbohydrazonoyl chloride in ethanolic solution of sodium ethoxide at room temperature yielded the thiohydrazonate ester 177 in 89\% yield (Scheme 72). ${ }^{97}$ The latter esters 177 were cleaved upon heating in benzene and hydrochloric acid to give benzoic $N$-(2,4-dibromophenyl)hydrazide and 1-phenyltetrazole-5-thione $\mathbf{1 7 6}$ (Scheme 72). ${ }^{96,97}$ When the 
thiohydrazonate esters $\mathbf{1 7 7}$ were heated with sodium ethoxide in ethanol under reflux, they were reported to give the substituted dihydrotetrazines derivatives $\mathbf{1 8 0}$. In each case, the latter products were accompanied by lesser yields of the symmetrical tetrazines $181 .{ }^{98}$

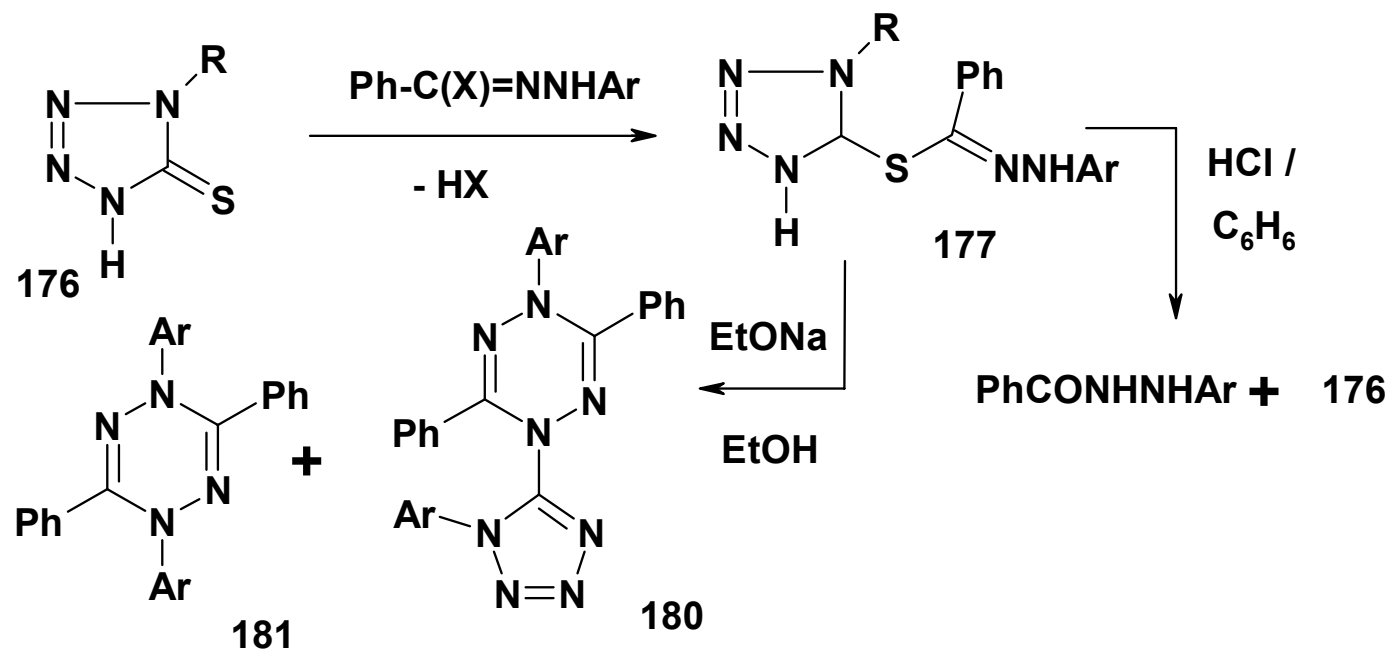

$$
\begin{aligned}
& \mathrm{Ar}=2,4-\mathrm{Br}_{2} \mathrm{C} 6 \mathrm{H}_{3}, 4-\mathrm{O}_{2} \mathrm{NC}_{6} \mathrm{H}_{4} \\
& \mathrm{R}=\mathrm{Ph}, 4-\mathrm{O}_{2} \mathrm{NC}_{6} \mathrm{H}_{4}, 4-\mathrm{MeC}_{6} \mathrm{H}_{4}, 4-\mathrm{MeOC}_{6} \mathrm{H}_{4}
\end{aligned}
$$

Scheme 72

\section{Functional group transformation}

Literature reports indicate that in some reactions of heterocyclic thiones with hydrazonoyl halides, the initially formed spirocycloadducts are unstable so that they undergo in situ ringchain tautomerism to give the respective $\mathrm{N}$-aryl-N-heteroaryl-thiocarbohydrazides as end products. For example, reactions of hydrazonoyl halides with each of 4,5-diaryl-1,2,4-triazole-3thiones $\mathbf{1 8 2},^{18,19,99} 5$-substituted-1,3,4-thiadiazole-2-thiones $\mathbf{1 8 3}^{100}$ and 4,6-disubstituted-3thioxo-1,2,4-triazin-5(4H)-one $\mathbf{1 8 4}^{45}$ afforded the thiocarbohydrazides $\mathbf{1 8 5}-\mathbf{1 8 7}$, respectively (Scheme 73). 


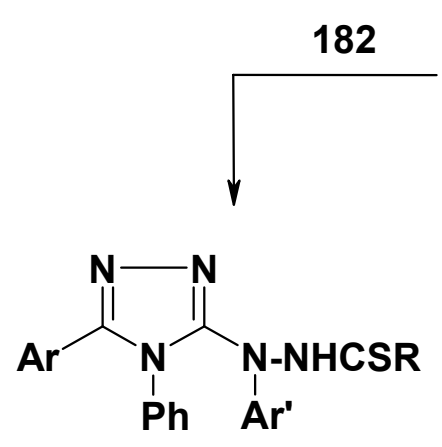

185

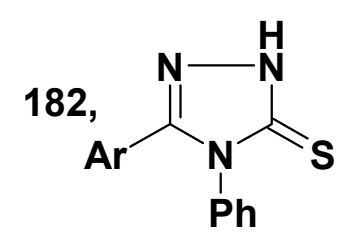<smiles>[R]c1n[nH]c(=S)s1</smiles>
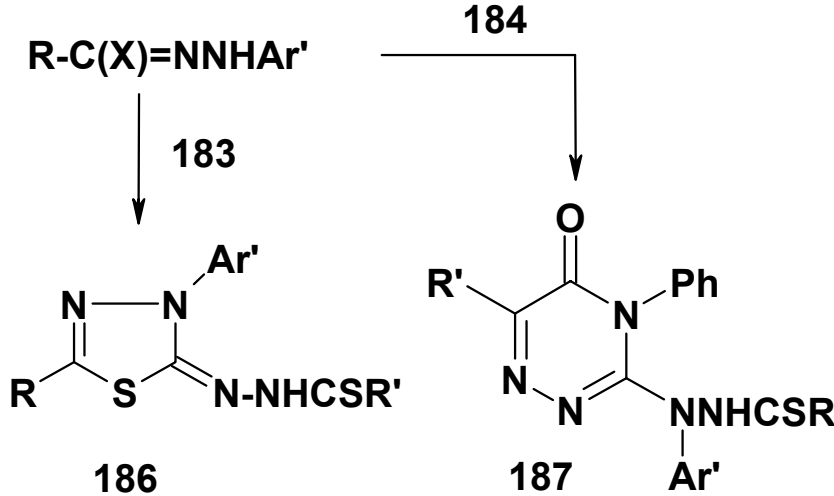

$$
\begin{aligned}
& \mathbf{R}=\mathrm{Ph}, \text { EtOCO, Ac, PhNHCO, PhCO } \\
& \mathbf{R}^{\prime}=\text { ArCONH }
\end{aligned}
$$<smiles>[R16]c1n[nH]c(=S)n(-c2ccccc2)c1=O</smiles>

\section{Scheme 73}

\section{Conclusions}

The present review has outlined the importance of the reactions of hydrazonoyl halides with heterocyclic thiones as convenient methodology for annulation of heterocycles, synthesis of spiro heterocycles and heterocyclic ring transformation. It is hoped that it will further stimulate interest in the chemistry of such halides and their use as popular synthons for other heterocycles of industrial and biological potentials. The reactions covered still require further exploration and applications.

\section{References}

1. Shawali, A. S.; Parkanyi, C. J. Heterocycl. Chem. 1980, 17, 833.

2. Shawali, A. S. Heterocycles 1983, 20, 2239.

3. Shawali, A. S. Chem. Rev. 1993, $93,2731$.

4. Shawali, A. S.; Abdallah, M. A. Adv. Heterocycl. Chem. 1995, 63, 277.

5. Shawali, A. S. J. Heterocycl. Chem. 2001, 38, 541.

6. Shawali, A. S.; Mosselhi, M. A. N. J. Heterocyclic Chem. 2003, 40, 725. 
7. Shawali, A. S.; Mosselhi, M. A. N. J. Sulfur Chem. 2005, 26, 267

8. Shawali, A. S.; Edrees, M. M. ARKIVOC, 2006, (ix), 292.

9. Shawali, A. S.; Sherif, S. M. Current Org. Chem. 2007, 11, 773.

10. Butler, R. N.; Scott, F. L. Chem. Indust. 1970, 1216.

11. Shawali, A. S.; Elwan, N. M.; Awad, A. M. J. Chem. Res. 1997, (S) 268, (M) 1870.

12. Shawali, A. S.; Albar, H. A. Can. J. Chem. 1986, 64, 871.

13. Shawali, A. S.; Abdelkhalek, A. A.; Sayed, A. R. J. Chin. Chem. Soc. 2001,48, 693.

14. Abdelhamid, A. O.; Attaby, F. A. J. Heterocycl. Chem. 1991, 28, 41.

15. Elwan, N. M.; Fahmy, A. A.; Abdallah, T. A.; Hassaneen, H. M. Sulfur Lett. 1994, $18,9$.

16. Shawali, A. S.; Abdallah, M. A.; Mosselhi, M. A. N.; Elewa, M. S. J. Heterocycl. Chem. 2007, 44, 285.

17. Shawali, A. S.; Mosselhi, M. A. N.; Farghaly, T. A. J. Chem. Res. 2007, 479.

18. Mosselhi, M. A. N.; Abdallah, M. A.; Riyadh, S. M.; Harhash, A. E.; Shawali, A. S. J. Prakt. Chem. 1998, 340, 160.

19. Abdallah, M. A.; Mosselhi, M. A. N.; Riyadh, S. M. ; Harhash, A. E. ; Shawali, A. S. J. Chem. Res. 1998, (S) 700, (M) 3038.

20. Shawali, A. S.; Abdallah, M. A.; Abbas, I. M.; Eid, G. M. J. Chin. Chem. Soc. 2004, 51, 351 .

21. Shawali, A. S.; Abdallah, M. A.; Zayed, M. E. M. J. Chin. Chem. Soc. 2002, 49, 1035.

22. Shawali, A. S.; Zeid, I. F.; Abdelkader, M. H.; Elsherbini A. A.; Altalbawy, F. M. A. J. Chin. Chem. Soc. 2001, 48, 65.

23. Mosselhi, M. A. N.; Abdallah, M. A.; Mohamed, Y. F.; Shawali, A. S. Phosphorus, Sulfur, Silicon 2002, 177, 487.

24. Abdallah, M. A.; Riyadh, S. M.; Abbas I. M. ; Gomha, S. M. J. Chin. Chem. Soc. 2005, 52, 987.

25. Dawood, K. M.; Farag A. M.; Abdelaziz, H. A. Heteroatom Chem. 2005, 16, 621.

26. Shawali, A. S.; Abdallah, M. A.; Mosselhi, M. A. N.; Mohamed, Y. F., Z. Naturforsch. 2002, 57B, 552 .

27. Fahmi, A. A.; Algharib, M. S., Zagazig. J. Pharm. Sci. 1995, 4, 267.

28. Abdelgawad, S. M.; Elgendi, M. S.; Abdelhamid, A. O. J. Sulfur Chem. 2005, 26, 21.

29. Abdelhamid A. O.; Altoom, A. Synthetic Commun. 2006, 36, 97.

30. (a) Abdelhamid A. O.; Ismail Z. H.; El-Gendy M. S.; Ghorab M. M. Phosphorus, Sulfur \&Silicon 2007, 182, 2409.

31. Abdelhamid A. O.; Aldelaziz H. M. Phosphorus, Sulfur \&Silicon 2007, 182, 2791.

32. Abdelhamid A. O; Alkhodishi M. A. M. Phosphorus, Sulfur \&Silicon 2005, 180, 149.

33. Shawali, A. S.; Elghandour, A. H.; Sayed, A. R. Synthetic Commun. 2001, 31, 731.

34. Shawali, A. S.; Abdallah, M. A.; Mosselhi, M. A. N.; Farghaly, T. A. Heteroatom Chem. 2002, 13, 136.

35. Mosselhi, M. A. N. Mon. Chem. 2002, 133, 1297. 
36. Mosselhi, M. A. N.; Abdallah, M. A.; Farghaly, T. A.; Shawali, A. S. Monatsh. Chem. 2004, $135,211$.

37. Shawali, A. S.; Abbas I. M.; Mahran, A. M. J. Iranian Chem. Soc. 2004, 1, 33.

38. Shawali, A. S.; Mahran, A. M.; Nada, A. A. Heteroatom Chem. 2007, 18, 393.

39. Hassaneen, H. M.; Abdelhadi, H. A.; Abdallah, T. A. Tetrahedron 2001, 57, 10133.

40. Riyadh, S. M. J. Chin. Chem. Soc. 2005, 52, 545.

41. Shawali, A. S.; Hilal, R. H.; Elsheikh, S. Monatsh. Chem. 2001, 132, 715.

42. Shawali, A. S.; Elghandour, A. A.; Elsheikh, Elsheikh, S. M. Heteroatom Chem. 2000, 11, 87.

43. Shawali, A. S.; Abdallah, M. A.; Zayed, M. E. M. J. Heterocycl. Chem. 2002, 39, 45.

44. Shawali, A. S.; Sayed, A. R. J. Chem. Res. 2004, 399.

45. Mansour, A. K.; Elwan, N. M.; Abdelhadi, H. A.; Abdallah, T. A.; Hassaneen, H. M. Sulfur Lett. 1995, 18, 105.

46. Shawali, A. S.; Gomha, S. M. J. Prakt. Chem. 2000, 342, 599.

47. Shawali, A. S. ; Elghandour, A. A. ; Elsheikh, S. M. J. Prakt. Chem. 2000, 342, 96.

48. El-Messaoudi, M.; Hasnaoui, A.; El-Mohtadi, M.; Lavergne, J. P. Bull. Soc. Chim. Belg. $1992,10,977$.

49. Hassan, N. M.; Abdelhamid, A. O. J. Chem. Res. 1997, (S) 350, (M) 2244.

50. Abdelhamid, A. O.; Metwally, N. H.; Bishai, N. S. J. Chem. Research 2000, (S) 462, (M) 1144.

51. Shawali A. S.; Sayed, A. R. J. Chem. Research 2005, 285.

52. Hassaneen, H. M.; Shawali, A. S.; Khalil, M. S.; Abdallah, T. A. Heterocycles 1993, 36, 1775.

53. Farag, A. M.; Dawood, K. M. Heteroatom Chem. 1997, 8, 129.

54. Shawali, A. S. ; Mosselhi, M. A. N.; Tawfik, N. M. J. Org. Chem. 2001, 66, 4055.

55. Mosselhi, M. A. N.; Hussein, A. M.; Shawali, A. S. J. Chin. Chem. Soc. 2006, 53, 923.

56. Abdelhadi, H. A.; Abdelhadi, T. A.; Hassaneen, H. M. Heterocycles 1995, 41, 1999.

57. Abdallah, M. A. Monatsh. Chem. 2001, 132, 959.

58. Abdelhamid, A. O.; Elghandour, A. H.; Ahmed, S. A.; Zaki, Y. H. J. Sulfur Chem. 2005, 26, 405.

59. Hassaneen, H. M.; Abdallah, T. A. Molecules 2003, 8, 333.

60. Shawali, A. S.; Mosselhi, M. A. N.; Hussein, A. M. J. Sulfur Chem. Soc. 2006, 27, 329.

61. Abdallah, T. A.; Darwish, M. A.; Hassaneen, H. M. Molecules 2002, 7, 494.

62. Shawali, A. S.; Mosselhi, M. A. N.; Farghaly, T. A. Phosphorus, Sulfur \& Silicon 2005, 52, 2391.

63. Abdallah, M. A. Z. Naturforsch. 2002, 57b, 699.

64. Riyadh, S. M.; Abdallah, M. A.; Abbas, I. M.; Gomha, S. M. Intern. Pure \& Appl.Chem. 2006, 1,75 .

65. Abbas, I. M.; Riyadh, S. M.; Abdallah M. A.; Gomha S. M. J. Heterocycl. Chem. 2006, 43, 935. 
66. Shawali, A. S.; Ali, N. A. H.; Ali, A. S.; Osman, D. A. J. Chem. Res. 2006, 323.

67. Hassan, N. A. J. Sulfur Chem. 2006, 27 (6), 605.

68. Elgazzar, A. B. A.; Gaafar, A. M.; Hafez H. N.; Aly, A. S. Phosphorus, Sulfur \& Silicon 2006, 181, 1859.

69. Hassaneen, H. M.; Daboun, H. A.; Abdelhadi, H. A.; Abdel-Reheem, N. A. Phosphorus, Sulfur \& Silicon 1995, 107, 269.

70. Elwan, N. M.; Abdelhadi, H. A. Zagazig. J. Pharm. Sci. 1995, 4, 205.

71. Hassaneen, H. M.; Shawali, A. S.; Farag, D. S.; Ahmed, E. M. Phosphorus, Sulfur \& Silicon 1996, 113, 53.

72. Buchel, T.; Prewo, R.; J. H. Bieri, J. H.; Heimgartner, H. Helv. Chim. Acta 1984, 67, 534.

73. Huisgen, R.; Crashey, R; Seidel, M.; Knupfer, H.; Schmidt, R. Ann. Chem. 1962, 169.

74. Poirier, Y. Bull. Soc. Chim. France 1967, 1203.

75. Grubert, L.; Patzel, M.; Jugelt, W.; Riemer, B.; Liebscher, J. Liebigs Ann. Chem. 1994, 1005.

76. Oparin, D. A.; Matylevich, Zh. V.; Galishev, V. A. Zh. Org. Khim. 1993, 29, 2321; Chem. Abstr. 121: 205293m.

77. Collins, D.; Hughes, T.; Johnson, W. M. Aust. J. Chem. 2000, 53, 137.

78. Abouricha, S.; Rakib, E.; Benchat, N. ; Alaou, M.; El Bali, H. B. Syn. Commun. 2005, 35, 2213.

79. Budarina, E. V.; Labeish, N. N.; Bel'skii V. K.; Galishev V. A. Russian J. Org. Chem. 2005, 41,758 .

80. Labeish, N. N.; Oparin, D. A.; Bel'skii, V. K; Galishev, V. A. Russ. J. Org. Chem. 1997, 33, 381; Chem. Abstr. 128: 167386d.

81. Oparin, D. A; Motovilin, D. B.; Galishev, V. A. Zh. Org. Khim. 1992, 28, 1100; Chem. Abstr. 118: 80872d.

82. (a) Baruah, A. K.; Prajapati, D.; Sandhu, J. S. Tetrahedron 1988, 44, 6137.

83. Redhouse, A. Acta Crystallogr.(C) 1990, 46, 1572; Chem. Abstr. 113: 221807x.

84. Sain, B.; Prajapati, D.; Mahajan,A. R.; Sandhu, J. S. Bull. Soc. Chim. Fr. 1994, 131, 313.

85. Oparin, D. A.; Yakovlev, S. D.; Motovilin, D. B.; Galishev, V. A. Zh. Org. Khim. 1992, 28, 1317; Chem. Abstr. 118: 147523r.

86. Rakib, E.; Benchidmi, M.; Essassi, E.; El Bouadili, A.; Khouli, M.; Barbe, J. M.; Pujol, M. D. Heterocycles 2000, 53, 571; Chem. Abstr. 132: 293746s.

87. Hemming, K.; Luheshi, A. N. ; Redhouse, A. D.; Smalley, R. K.; Thompson, J. R. Tetrahedron 1993, 49, 4383.

88. Abbas, I. M.; Abdallah, M. A.; Mosselhi, M. A. N.; Mohamed, S. Z.; Shawali, A. S. J. Chem. Res., (S) 1994, 308.

89. Mosselhi, M. A. N.; Abdallah, M. A.; Abbas, I. M.; Mohamed, S. Z.; Shawali, A. S. J. Chem. Res. 1995, (S) 83, (M) 646.

90. Shawali, A. S.; Abdallah, M. A.; Zayed, M. E. M. Z. Naturforsch. 2000, 55b, 546.

91. Abdelhamid A. O.; Abdelwahab, B. A. M. Afinidad 2004, 61, 65 
92. Moustapha C.; Abdel-Riheem N. A.; Abdelhamid, A. O. Synth. Commun. 2005, 35, 249.

93. Zaki Y. H.; Ahmed S. A.; Hussein A. M.; Abdelhamid A. O. Phosphorus, Sulfur \& Silicon 2006, 181,825 .

94. (a) Abdallah, M. A.; Riyadh, S. M.; Abbas I. M.; Gomha, S. M. Intern. Pure \& Appl. Chem. 2006, 1 (2), 265.

95. Greig, D. J.; Mcpherson, M.; Paton R. M.; Crosby, J. J. Chem. Soc (P1) 1985, 1205.

96. Butler, R. N.; NiBhradaigh, E. P.; Fitzgerald, K. J. J. Chem. Res. 1993, (S) 306, (M) 1948.

97. Elliott, A. J., Callaghan, P.D., Gibson, M. S., Nemeth, S. T. Can. J. Chem. 1975, 53, 1484.

98. Butler, R. N.; NiBhradaigh, E. P.; McArdle, P.; Cunnigham, D. J. Chem. Res. 1995, (S) 224, (M) 1401 .

99. Mosselhi, M. A. N.; Abdallah, M. A.; Riyadh S. M.; Shawali, A. S. Indian J. Chem. 2005, $44 B, 176$.

100.Abdallah, M. A. ; Mosselhi, M. A. N. ; Abbas, I. M. ; Fahmi, A. A.; Shawali, A. S. J. Chem. Res. 1995, (S) 370 .

\section{Biographical Sketches}

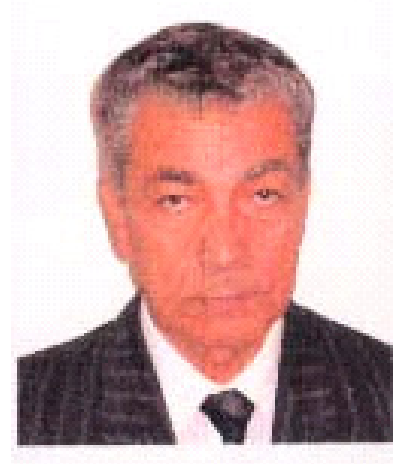

Ahmad Sami A. S. Shawali is presently Professor of Physical organic chemistry in the Chemistry Department, Faculty of Science, University of Cairo. He graduated with B.Sc. degree from the same university in 1958. He received his M.Sc. and Ph.D. degrees in 1962 and 1966, respectively, from Lowell Technological Institute, presently The University of Lowell, Lowell, Massachusetts, USA. He was awarded the degree of Doctor of Science (D.Sc.) from British Royal Chemical Society and the University of Cairo in 1995. Prof. Shawali has been the recipient of the state award for science and Egypt State Medal of Science and Arts in 1977. He holds several national and international certificates of merit for his distinguished services. He was visiting professor at the university of Texas, El Paso, Texas, USA from 1979 to 1980, University of Kuwait from 1973 to 1977 and King Abdulaziz University, Jeddah, Saudi Arabia from 1982 to 1988. He was appointed Vice-Dean for student affairs in 1989, then he was elected Dean of the Faculty of Science in 1991. He published 204 papers including 8 review articles in 
the fields of reaction mechanisms, applications of LFERs, chemistry of hydrazonoic acid derivatives, 1,3-dipolar cycloaddition and electrocyclization of nitrilimines. At present the average numbers of citations of his work by other authors are 50/year and 9/paper.

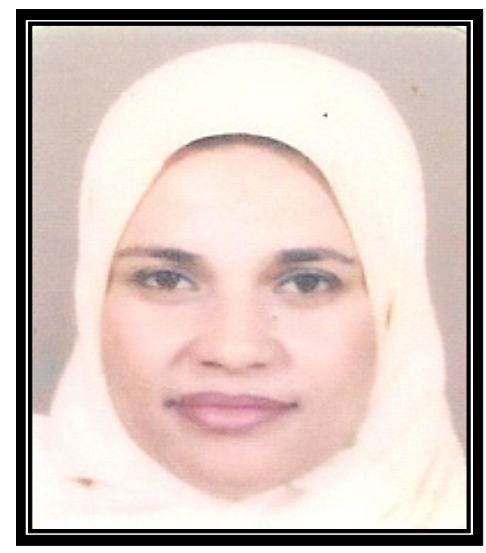

Thoraya Abd Elreheem Farghaly was born in Cairo, Egypt in 1974. She received her B.Sc. (1996); M.Sc. (2002) and Ph.D. (2005) degrees from University of Cairo. At present, She is Assistant Professor of organic chemistry in the Chemistry Department, Faculty of Science, University of Cairo. She joined the scientific school of Prof. A. S. Shawali in 1997 and conducted several research projects in the area of the chemistry of hydrazonoyl halides and heterocyclic chemistry. 